IZA DP No. 8838

The Welfare Effects of Asset Means-Testing Income Support

Felix Wellschmied

February 2015 


\title{
The Welfare Effects of Asset Means-Testing Income Support
}

\author{
Felix Wellschmied \\ Universidad Carlos III de Madrid \\ and IZA
}
Discussion Paper No. 8838
February 2015

\author{
IZA \\ P.O. Box 7240 \\ 53072 Bonn \\ Germany \\ Phone: +49-228-3894-0 \\ Fax: +49-228-3894-180 \\ E-mail: iza@iza.org
}

Any opinions expressed here are those of the author(s) and not those of IZA. Research published in this series may include views on policy, but the institute itself takes no institutional policy positions. The IZA research network is committed to the IZA Guiding Principles of Research Integrity.

The Institute for the Study of Labor (IZA) in Bonn is a local and virtual international research center and a place of communication between science, politics and business. IZA is an independent nonprofit organization supported by Deutsche Post Foundation. The center is associated with the University of Bonn and offers a stimulating research environment through its international network, workshops and conferences, data service, project support, research visits and doctoral program. IZA engages in (i) original and internationally competitive research in all fields of labor economics, (ii) development of policy concepts, and (iii) dissemination of research results and concepts to the interested public.

IZA Discussion Papers often represent preliminary work and are circulated to encourage discussion. Citation of such a paper should account for its provisional character. A revised version may be available directly from the author. 
IZA Discussion Paper No. 8838

February 2015

\section{ABSTRACT}

\section{The Welfare Effects of Asset Means-Testing Income Support}

This paper quantitatively determines the asset limit in income support programs which minimizes consumption volatility in a lifecycle model with incomplete markets and idiosyncratic earnings risk. An asset limit allows allocating transfers to those households with the highest utility gains from extra consumption. Moreover, it serves as substitute for history and age dependent taxation. However, a low limit provides incentives for high school dropouts to accumulate almost no wealth. Consequently, they miss self-insurance and suffer from high consumption volatility. For an unborn, these effects are optimally traded-off with an asset limit of $\$ 145000$.

JEL Classification: D91, I38, J26

Keywords: means-tested programs, public insurance, incomplete markets

Corresponding author:

Felix Wellschmied

Universidad Carlos III de Madrid

Calle Madrid 126

28903, Getafe

Spain

E-mail: fwellsch@eco.uc3m.es

\footnotetext{
* I am thankful for comments from Rüdiger Bachmann, Christian Bayer, Andrew Clausen, Hans-Martin v. Gaudecker, Thomas Hintermaier, Mark Huggett, Alexander Kriwoluzky, Keith Kuester, Moritz Kuhn, Iourii Manovskii, Monika Merz, Michael Reiter, Petr Sedláček, Kjetil Storesletten, Volker Tjaden, and participants at the $4^{\text {th }}$ Ifo Conference on Macroeconomics and Survey Data, the 2012 Cologne Workshop on Macroeconomics, the 2013 European Macroeconomics Workshop, the Bundesbank/FU Workshop, the Federal Reserve Board, the Federal Reserve Bank of Philadelphia, the ZEW, and the Universities of Adelaide, Bonn, Carleton, Carlos III, Catolica de Chile, Missouri, Oslo, Queensland, and Vienna. I gratefully acknowledge support from the Deutsche Forschungsgemeinschaft (DFG) through the Bonn Graduate School of Economics.
} 


\section{Introduction}

Between 1996 and 2007, around 13 percent of US households received transfers from asset means-tested income support programs. For 40 percent of these households, these transfers were even the dominant source of income. The means-test assures that only households receive transfers which assets are below a certain limit, which was less than $\$ 5000$ in most US states. Means-testing imposes an implicit tax on savings. Households may impoverish themselves and miss private means to finance consumption after poor labor market outcomes or during retirement. Partly driven by these concerns, recent reforms greatly relaxed the asset means-test (see Federal Budget, 2011). However, some level of means-testing may actually increase social welfare, because it allocates transfers to those households which have the largest utility gains.

This paper computes the asset limit which leads to the lowest consumption volatility in a life-cycle framework with persistent earnings shocks and transitory but large shocks arising from non-employment. I identify the earnings process in micro data from the Survey of Income and Program Participation (SIPP) and parametrize it in a structural, small open economy model with incomplete markets. The framework implies three reasons for the policy maker to invoke a means-test. First, because households use assets as self-insurance, those with few assets have the highest utility gains from transfers. Second, a means-test serves as a partial substitute for history dependent taxation. As households run down assets after repeated poor labor market outcomes, a means-test allows targeting transfers towards households with persistent, instead of transitory, low earnings. Third, the life-cycle dimension implies welfare gains from age specific transfers. Young households have many household members and expected future earnings growth. This creates incentives providing more transfers early in life. Because these households tend to have low assets, a meanstest achieves exactly this. The optimal policy has to weight these gains from the means-test against the savings distortions that it inflicts.

I show that the strength of the distortions depends on a household's education (earnings potential) and age. As in the more stylized model of Hubbard et al. $(1994,1995)$, those with low education are the most likely to 
pass the earnings-test; thus, they have the weakest incentives accumulating assets. In my model, savings are less distorted than in their framework, because I allow for strictly positive asset limits, and households value bequest; hence, desire holding assets late in life. Nevertheless, throughout the life-cycle, at least 20 percent of high school dropouts have less than $\$ 8000$ in assets. Regarding the effect of age, elderly households react stronger to the means-test than prime-aged households because the latter aim accumulating assets for retirement and bequests.

My welfare measure, similar to Conesa et al. (2009), compares two unborn cohorts to whom the government provides the same amount of total transfers. One cohort is born when the government employs an asset means-test additional to an earnings test, and the other is born when transfers depend only on earnings. Thus, in the latter case, households under financial distress receive less transfers, there is no longer an implicit discrimination between persistent and transitory earnings losses, and no implicit age specific taxation. The reform keeps the total amount of transfers to each education group fixed. Therefore, it avoids welfare responses resulting from the desire of reallocation towards the low educated present in my framework. ${ }^{1}$

I start by studying the implications of abolishing the means-test of $\$ 5000$. An unborn household is willing to forgo 0.26 percent of life-time earnings to not abolish the means-test. Quantifying the different mechanisms, I find that an unborn household is willing to pay 0.3 percent of life-time earnings because the means-test allocates more transfers to young households and 0.12 percent for the implicit history dependence in transfers. Without these effects, the savings distortions would outweigh the insurance mechanisms from the means-test. The numbers hide much larger welfare effects at the disaggregated level. An unborn high school dropout is willing to forgo 5.6 percent of lifetime earnings to abolish the means-test. Contrary, higher educated households prefer not to abolish it.

Increasing the asset limit mitigates the adverse incentive effects for high school dropouts while preserving much of the insurance effect for the higher educated. Compared to no means-test, welfare is highest with an asset limit

\footnotetext{
${ }^{1}$ Recently, Heathcote et al. (2014) provide a discussion on the desirability to insure households against inequality of initial conditions.
} 
of $\$ 145000$. An unborn household is willing to forgo 1.2 percent of lifetime earnings to not abolish it. Welfare starts decreasing again with even higher limits because there are relatively little gains left from making choices less distorted.

To lend validity to my welfare results, I demonstrate that the data is consistent with the incentive effects of the means-test. In line with available reduced form estimates, I find a statistically significant increase of savings of young households in response to a rise in the asset limit (see Powers, 1998), but an insignificant response for prime aged households (see Hurst and Ziliak, 2006). My simulation is also consistent with small reductions of total assets as a response to a rise in means-tested transfers (see Neumark and Powers, 1998; Ziliak, 2003). Qualitatively in line with the model predictions, at least 15 percent of households hold almost no assets at all ages in the data, and low asset holdings are concentrated at low educated households (see Dynan et al., 2004). Finally, the model is consistent with the finding of Blundell et al. (2008) that particularly consumption of households with low education responds to income shocks.

The welfare effects arise purely from changes in consumption volatility given exogenous earnings. This complements the existing literature which focuses on the response of labor supply to the means-test. Golosov and Tsyvinski (2006) study incentives to claim disability insurance, Rendahl (2012) the search behavior of the unemployed, and Pashchenko and Porapakkarm (2013) the labor force participation decision. Recent papers which study insurance effects of non-means-tested programs include Krueger and Kubler (2006) (Social Security) and Pavoni and Violante (2007) and Low et al. (2010) (unemployment insurance). I find that large transfers from these programs to households with low income become more desirable when means-testing is present in other support programs. The reason is that in the presence of the means-test more households fail accumulating sufficient assets to smooth transitory shocks and to prepare for the drop in earnings upon retirement.

The paper is structured as follows. Section ?? present the model. Section 2 provides intuition for the savings distortions. The section thereafter discusses the calibration of the model. Section 4 shows that the mechanisms of the model find support in the data. Section 5 conducts the welfare anal- 
ysis, and the final section conclude. I delegate additional information to an Appendix. ${ }^{2}$

This section specifies the model in which households make consumption decisions under risk. Insurance against the risk may come in form of private insurance, governmental insurance, or self-insurance by means of asset accumulation. With regard to private insurance, I assume that there is perfect insurance within the household, and I allow households to insure against earning changes of the "main earner". What matters for households' decisions is how much risk remains after governmental transfers which do not use an asset means-test. I explicitly model the largest of these programs. Finally, how much households are willing to reduce their assets as a response to the means-test depends on their desires for holding assets which are not for precautionary and retirement purposes. Hence, I explicitly model high health expenditures in old age and a bequest motive (see De Nardi et al., 2010).

\subsection{Demographics, Labor Market Risk and Health Expenditures}

The economy is populated by a unit mass of households which make consumption decisions on a quarterly basis. A household dies in quarter $h$ with probability $\iota_{h}\left(\mu_{1}\right)$ and dies with certainty after $H$ quarters. $\mu_{1}$ is the exogenous education level (innate ability) of the household which I specify below. When a household dies, it is replaced by a newborn household. Similar to Scholz et al. (2006), household composition changes deterministically over the life-cycle. At age $h$, its size is given by $N_{h}$.

From the perspective of an unborn, a household faces three major types of earnings' risk. First, at labor market entry, it draws one of four permanent education level $\mu_{1}$ (high school dropout, high school graduate, some college, and college). The predictable part of households' earnings evolves according to $\mu_{h}=\mathcal{F}\left(\mu_{1}, h\right)$. Second, until age $H_{160}$ (65 years), the household faces shocks to its persistent earnings component, $\varphi_{h}$, which intendeds to capture the uncertainty from changes in households' labor-market

\footnotetext{
${ }^{2}$ The numerical routine and codes for the data are available from the author upon request.
} 
possibilities. $\varphi_{h}$ follows a mean-zero Markov process. When employed, a household's earnings are given by:

$$
\begin{aligned}
& \ln \left(w_{h}\right)=\mu_{h}+\varphi_{h} \\
& \pi_{j, k}=\operatorname{prob}\left[\varphi_{h}=\varphi^{k} \mid \varphi_{h-1}=\varphi^{j}\right] .
\end{aligned}
$$

From age $H_{160}+1$ onwards, a households' persistent earnings component remains unchanged:

$$
\ln \left(w_{h}^{r}\right)=\mu_{h}+\varphi_{H_{160}+1} .
$$

Third, households face spells of non-employment. When employed, it moves to non-employment with probability $\delta_{h}\left(\mu_{1}\right)$. When non-employed, it finds a new job with probability $\lambda_{h}\left(\mu_{1}\right)$. The age component in these flow rates represents the gradual withdrawal of households from the labor market over the life-cycle. Representing household insurance against unemployment risk of the main earner, I allow for positive earnings during non-employment until age $H_{160}$ :

$$
w_{h}^{u}=\gamma\left(\mu_{1}, h\right)
$$

From age $H_{160}+1$ onwards, households have to pay deterministic outof-pocket medical expenditures $\mathcal{M}\left(\mu_{h}\right)$. These expenditures depend on the education level of the household. This simple way of modeling exogenous health expenditures captures the fact that households with higher earnings choose to buy more medical services.

\subsection{Governmental Insurance and Private Pensions}

The government provides insurance against labor market and longevity risk. These insurance schemes come of two types: non-means-tested and asset means-tested insurance. Appendix A and Appendix B provide additional information on the amount of transfers and the role of labor market earnings for the non-means-tested and means-tested programs, respectively. ${ }^{3}$

\footnotetext{
${ }^{3}$ For more detailed information, Moffitt (2003) provides an excellent summary of means-tested programs.
} 


\subsubsection{Non-Means-Tested Transfers}

For tractability, I simplify the Social Security legislation. Households claim this additional income with certainty at age $H_{160}+1$, and I assume that the system replaces a constant fraction of a household's last earnings possibility: ${ }^{4} S=\mathcal{S}\left(\mu_{H_{160}}, \varphi_{H_{160}}\right)$. Additionally, households may receive private pensions from age $H_{160}+1$ onwards. The wealth accumulated in private pensions does not count against the asset means-test. Therefore, it has similar saving incentives to Social Security. Similarly to the latter, I assume that pension payments depend only on the last earnings possibility instead of the history of earnings: $P_{h}=\mathcal{P}\left(\mu_{H_{160}}, \varphi_{H_{160}}, h\right)$.

Additionally, the government runs an non-employment insurance program before households reach the age of $H_{160}$. The insurance is supposed to mimic legislation in the US where benefits $b_{h}$ replace a constant fraction of earnings $w_{h}$ subject to a cap of $b^{\max } .{ }^{5}$ The insurance is paid only temporarily, i.e., the period after the job loss:

$$
b_{h}=\min \left\{\nu w_{h}, b^{\max }\right\}
$$

Another way of insuring households against earnings risk is the progressive income tax code. In formulating the problem, I assume households pay income taxes on labor market earnings up to age $H_{160}$ and compute Social Security as a replacement rate of net earnings. Let $\tau\left(w_{h}\right)$ denote the tax, which may be negative because of earned income tax credits. Then define

\footnotetext{
${ }^{4}$ In reality, households may chose to claim benefits early. Moreover, replacement rates depend on a workers entire earnings history. An additional state variable makes the numerical approximation infeasible. The current modeling choice makes earnings shocks towards retirement very persistent; hence, leads to too strong consumption adjustments before retirement. It is unclear whether this makes means-testing more or less attractive. On the one hand, means-testing implies additional insurance in case of very poor outcomes before retirement. On the other hand, households hold fewer assets and cannot react to these poor outcomes by means of self-insurance.

${ }^{5}$ Strictly speaking, $w_{h}$ is never realized because the household is unemployed. The legislation conditions benefits on last period earnings. However, this would introduce an additional state variable into the problem. Given that $\varphi_{h}$ is very persistent, current period earnings are very similar to past period earnings.
} 
total household gross and net earnings as:

$$
\begin{aligned}
& E_{h}^{g r o s s}=w_{h}+w_{h}^{u}+b_{h}+w_{h}^{r}+S+P_{h}, \\
& E_{h}^{n e t}=w_{h}\left(1-\tau\left(w_{h}\right)\right)+w_{h}^{u}+b_{h}+w_{h}^{r}+S+P_{h} .
\end{aligned}
$$

\subsubsection{Asset Means-Tested Transfers}

I make four simplifying assumptions with respect to the means-tested programs in place in the US at the beginning of the century. First, I assume that there is a $100 \%$ pick-up rate. Second, I calculate the dollar value of all in-kind transfers. ${ }^{6}$ Third, the government can perfectly observe savings $k_{h} \cdot{ }^{7}$ Finally, I assume a common asset and earnings threshold for all programs. $^{8}$ While differences between the programs exist, categorical eligibility, and thereby common thresholds, became wide spread in 1996, which is the beginning of my sample period.

I set the earnings threshold $E_{h}^{\text {elig }}$ to the gross earnings test from the Supplemental Nutrition Assistance Program (SNAP). The eligibility threshold and the transfers depend on household age because household size varies over the life-cycle. Most states allow for liquid wealth of up to $\$ 2000$. However, a household's vehicle is usually excluded from the means-test. Therefore, I impose an asset limit $\bar{a}$ of $\$ 5000$. Some states also allow allowances for a households' housing value. Housing might be less suited to insure against earnings shocks, but it may be important to finance consumption during retirement. Section 5.1.2 shows how the results change with different values of $\bar{a}$.

Two programs are available to households at all stages of their lifecycle. SNAP provides households with vouchers for food. The goal of the program is to make high quality nutrition food available to low income households. When eligible, the maximum amount of benefits is $\overline{T R}_{h}^{F}$, and the amount actually received is denoted by $T R_{h}^{F}$. The Low Income Home Energy Assistance Program (LIHEAP) provides energy assistance to house-

\footnotetext{
${ }^{6}$ Reassuring, all programs provide benefits that are quick to access and serve every day basic needs.

${ }^{7}$ If households could hide a fixed amount of savings, the only change would be a higher $\bar{a}$.

${ }^{8}$ All programs are initiated by the Federal Government. However, eligibility criteria differ across states both concerning the level of allowed income and resources.
} 
holds. Eligibility is usually guaranteed when a household participates in another welfare program, and I find little correlation between income and the amount of benefits in the data. Therefore, I assume that each eligible household receives a common amount of benefits which differs among working and retired households: $\overline{T R}_{W}^{H}$ and $\overline{T R}_{R}^{H}$.

Before reaching age $H_{160}$, the household may receive Temporary Assistance to Needy Families (TANF), formerly Aid to Families with Dependent Children $(A F D C)$, which provides cash and in kind transfers to families with children under 19 years of age. ${ }^{9}$ The latter serves basic needs such as child care, education, and transportation. Denote by $\overline{T R}^{T}$ the maximum amount of receivable benefits and $T R^{T}$ as the benefits after income deductions. Females who are pregnant or have children less than five years of age may be eligible to the Special Supplemental Nutrition Program for Women, Infants and Children (WIC). Households are eligible when they participate in any of the above programs, in which case they receive a flat transfer of $\overline{T R}^{W}$. Almost no household older than 38 years participates in the program, and I impose this limit in my model.

The total amount of benefits an eligible household receives is, thus:

$$
T R_{h}^{W}=T R_{h}^{F}+T R^{T}+\overline{T R}_{W}^{H}+\overline{T R}^{W} I_{<64}
$$

where $I_{<64}$ is an indicator variable which is one when the household is younger than 38 years.

After the age of $H_{160}$, households may receive benefits from Supplemental Security Income $(S S I) .{ }^{10}$ Denote by $\overline{T R}_{h}^{S}$ the maximum amount of receivable benefits and $T R_{h}^{S}$ as the benefits after income deductions. Moreover, households which satisfy the income and asset-test receive Medicaid which pays for their health expenditures. Total transfers to an elderly eligible households are, thus:

$$
T R_{h}^{R}=T R_{h}^{F}+T R_{h}^{S}+\overline{T R}_{R}^{H}+\mathcal{M}\left(\mu_{h}\right) .
$$

\footnotetext{
${ }^{9}$ Looking at data from the SIPP suggests that at all ages of working life a non-trivial fraction of households receives transfers.

${ }^{10}$ The legislation also allows non-retired disabled and blind children to participate which I abstract from.
} 
Households' eligibility depends on its choice of end of period wealth $k_{h}$ which pays certain return from the world capital market $(1+\mathrm{r}) .{ }^{11}$ Summarizing the above yields: ${ }^{12}$

$$
T R\left(k_{h}, E_{h}^{\text {gross }}, h\right)= \begin{cases}0 & \text { if } k_{h}>\frac{\bar{a}}{1+r} \text { or } E_{h}^{\text {gross }}>E_{h}^{\text {elig }} \\ T R_{h}^{W} & \text { if } k_{h} \leq \frac{\bar{a}}{1+r} \text { and } E_{h}^{\text {gross }} \leq E_{h}^{\text {elig }} \text { and } h \leq H_{160} \\ T R_{h}^{R} & \text { if } k_{h} \leq \frac{\bar{a}}{1+r} \text { and } E_{h}^{\text {gross }} \leq E_{h}^{\text {elig }} \text { and } h>H_{160}\end{cases}
$$

\subsection{The Household Problem}

The household takes as given initial beginning of period assets, its employment status, and the laws of motion for labor-market earnings. It chooses each period total consumption $c_{h}$ and implied end of period assets $k_{h}$. The household derives period utility from person equivalence consumption:

$$
U_{h}=\frac{\left(c_{h} \xi\left(N_{h}\right)\right)^{1-\gamma}}{1-\gamma}
$$

where $\gamma$ is the parameter of risk-aversion and $\xi$ is the person equivalence sale. The choice $k_{h}$ must come from the feasibility correspondence:

$$
\Gamma\left(a, E_{h}^{\text {gross }}, h\right)=\left\{\begin{array}{l}
a_{h}+E_{h}^{\text {net }}+T R\left(k, E_{h}^{\text {gross }}, h\right) \\
a_{h+1}=(1+r) k+T R\left(k_{h}, E_{h}^{\text {gross }}, h\right) \\
a_{h+1} \geq 0 .
\end{array}\right.
$$

Households can save at most their beginning of period assets plus their earnings and possible end of period transfers. They must satisfy a zero borrowing constraint for beginning of period assets. ${ }^{13}$ The motivation for a zero borrowing constraint is that those most affected by the income sup-

\footnotetext{
${ }^{11}$ The focus of this paper are the saving decisions of the relative poor which hold little of the country's capital stock. Therefore, changes in their savings behavior are unlikely to have major impacts on the equilibrium interest rate.

${ }^{12}$ Some readers may want to compare my specification to the one put forward by Hubbard et al. (1995). Abstracting from unemployment, which they have not as distinctive state, they specify $T R\left(k_{h}, w_{h}\right)=\max \left\{0, \bar{C}-\left[(1+r) k_{h}+w_{h}\right]\right\}$ where $\bar{C}$ is a guaranteed consumption floor. In this set-up, all households participating in the program choose $k_{h}=0$.

${ }^{13}$ The assumption is that households can borrow against end of period means-tested transfers.
} 
port programs have low credit ratings; therefore, their access to credit is strongly limited. ${ }^{14}$ Moreover, the borrowing constraint by itself is of little importance for the quantitative welfare implications of the means-test. ${ }^{15}$ Instead, what matters is the difference between the borrowing constraint and the maximum of assets allowed by the means-test.

I state the household problem recursively where primes denote next period values. A currently employed household of age $h$ with asset position $a$, education $\mu_{1}$, and persistent component $\varphi_{h}$ solves:

$$
\begin{aligned}
V_{h}\left(a, \varphi, \mu_{1}, E\right)= & \max _{k \in \Gamma}\left\{\frac{\left(\left[a+E_{h}^{n e t}-k\right] \xi\left(N_{h}\right)\right)^{1-\gamma}}{1-\gamma}\right. \\
& +\beta \mathbb{E}\left\{\left(1-\iota_{h}\left(\mu_{1}\right)\right) \mathbb{V}_{h}\left(a^{\prime}, \varphi^{\prime}, \mu_{1}, E\right)+\iota_{h}\left(\mu_{1}\right) \bar{V}\left(a^{\prime}\right)\right\},
\end{aligned}
$$

where $\mathbb{E}$ is the expectation operator, $\beta$ is the discount factor, and households consume $a+E_{h}^{n e t}-k$. In case the household dies, it values bequests according to $\bar{V}$. Similar to French and Jones (2011) I choose the following specification for bequests:

$$
\bar{V}(a)=\theta_{b} \frac{(a+Z)^{1-\gamma}}{1-\gamma}
$$

where $\theta_{b}$ guides the strength of the bequest motive. ${ }^{16}$ The parameter $Z$ assures that with probabilistic death, holding zero wealth is not ruled out. I set $Z=\$ 1000$. In case the household does not dye, it may continue being employed, or move into non-employment:

$\mathbb{V}_{h}\left(a^{\prime}, \varphi^{\prime}, \mu_{1}, E\right)=\left(1-\delta_{h}\left(\mu_{1}\right)\right) V_{h+1}\left(a^{\prime}, \varphi^{\prime}, \mu_{1}, E\right)+\delta_{h}\left(\mu_{1}\right) V_{h+1}\left(a^{\prime}, \varphi^{\prime}, \mu_{1}, U\right)$.

\footnotetext{
${ }^{14}$ I thank Dirk Krueger for pointing this out to me.

${ }^{15}$ For example, Kaplan and Violante (2010) use a very similar model environment and show that households have almost the same amount of self-insurance against persistent earnings shocks with a zero borrowing constraint or a natural borrowing constraint. Their Table 5 shows that this result is true as long as the autocorrelation of earnings is sufficiently close to one which will be true in my calibration.

${ }^{16}$ In an earlier version of the paper, I assumed that households care about the utility of their offspring with persistent skill transitions between generations. The results are very similar to this more reduced form.
} 
The value function of the non-employed solves:

$$
\begin{aligned}
V_{h}\left(a, \varphi, \mu_{1}, U\right)= & \max _{k \in \Gamma}\left\{\frac{\left(\left[a+E_{h}^{n e t}-k\right] \xi(N)\right)^{1-\gamma}}{1-\gamma}\right. \\
& +\beta \mathbb{E}\left\{\left(1-\iota_{h}\left(\mu_{1}\right)\right) \mathbb{V}_{h}\left(a^{\prime}, \varphi^{\prime}, \mu_{1}, U\right)+\iota_{h}\left(\mu_{1}\right) \bar{V}\left(a^{\prime}\right)\right\}
\end{aligned}
$$

$\mathbb{V}_{h}\left(a^{\prime}, \varphi^{\prime}, \mu_{1}, U\right)=\lambda_{h}\left(\mu_{1}\right) V_{h+1}\left(a^{\prime}, \varphi^{\prime}, \mu_{1}, E\right)+\left(1-\lambda_{h}\left(\mu_{1}\right)\right) V_{h+1}\left(a^{\prime}, \varphi^{\prime}, \mu_{1}, U\right)$

The household may either find a new job with probability $\lambda_{h}\left(\mu_{1}\right)$, or stay in non-employment. Note that net earnings $\left(E_{h}^{n e t}\right)$ include unemployment benefits only in the first period of job loss and for those which are not yet retired.

\section{Distortions from the Means-Test}

This section shows how the asset means-test creates welfare costs by distorting households' savings incentives. I relegate all proofs to Appendix C. Summarize the states $\mathbf{X}=\left(\varphi, \mu_{1}, Z\right)$, where $Z$ is the employment state. Let $k_{h}(a, \mathbf{X})$ be the optimal policy for end of period assets induced by the state vector in period $h$. Likewise, let $a_{h+1}(a, \mathbf{X})$ be the optimal policy for next period assets. ${ }^{17}$

I begin with characterizing policy of households which current earnings are sufficiently low to be eligible for the means-tested program. To this end, define the interval with length $\epsilon$ and center $k^{0}$ as $B_{\epsilon}\left(k^{0}\right)$.

Theorem 1. The policy $k_{h}(\cdot, \boldsymbol{X})$ is increasing. Yet, $\forall E_{h}^{\text {gross }} \leq E_{h}^{\text {elig }}$ there may exist $k_{h}(a, \boldsymbol{X}) \in B_{\epsilon}\left(k_{h}^{0}\left(a^{0}, \boldsymbol{X}\right)\right)$ with $k_{h}^{0}=\frac{\bar{a}}{1+r}$. But, $\exists \tilde{a}_{h}(\boldsymbol{X})$ s.th. $k_{h}\left(\tilde{a}_{h}, \boldsymbol{X}\right)>\frac{\bar{a}}{1+r} \forall a>\tilde{a}_{h}(\boldsymbol{X})$.

Despite the policy $k_{h}(\cdot, \mathbf{X})$ being monotone, the marginal propensity to consume out of additional assets may be one for households with low income and assets. Intuitively, the household weights the utility gains from consumption smoothing against the forgone transfer from choosing

\footnotetext{
${ }^{17}$ These correspondences are not necessarily single valued for a range of the state space given the problem stated in (1) and (2). I assume that the household chooses the larger $k_{h}$ when it is indifferent between choices. I show why non-uniqueness can arise and show that it is of little practical relevance.
} 
Figure I: Savings Behavior in $H$

(A) Objective Function in $H$

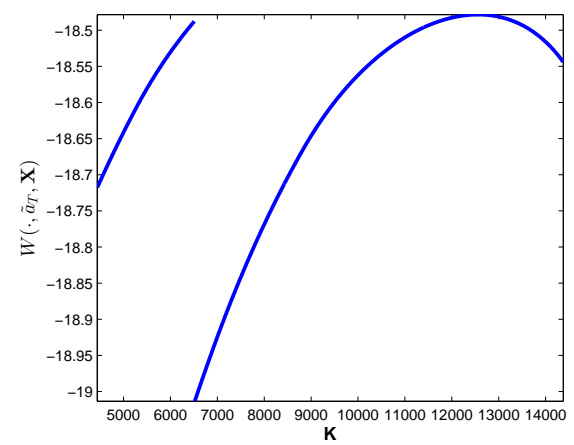

(B) Savings and Value Function in $H$

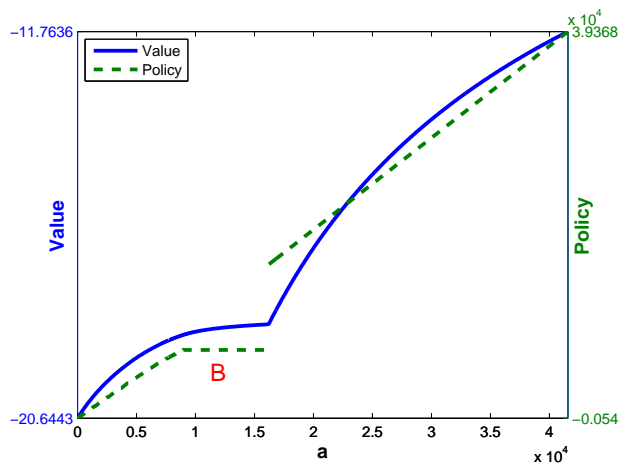

Notes: Panel $A$ depicts the objective function in $H$, i.e., the return from different admissible strategies in $H, K_{H}$. Panel $B$ displays the resulting policy and value function. Earnings are such that the household is eligible to the means-tested program. Asset units are expressed in $2004 \$$.

$k_{h}>\frac{\bar{a}}{1+r}$. To provide a better understanding for this trade-off, let me define the following objective function at $\left(\tilde{a}_{H}(\mathbf{X}), \mathbf{X}\right)$ :

$$
W_{T}\left(K, \tilde{a}_{T}, \mathbf{X}\right)=U\left(\tilde{a}_{H}+E_{H}^{n e t}-K\right)+\beta \bar{V}\left(a^{\prime}\right)
$$

Figure I (Panel A), depicts the function. The first local maximum is the choice $K=\frac{\bar{a}}{1+r}$. Choices just above this point lead to lower returns because the negative income effect dominates the additional consumption smoothing effect. Larger choices lead to additional gains from consumption smoothing, which are largest at the second local maximum. Panel $B$ shows the resulting value and policy function in period $H$. In the area $B$, households save exactly the maximum to still satisfy the means-test. The value function becomes relatively concave because of decreasing returns to this period consumption. This behavior inflicts a cost on social welfare. The social planner prefers that households equate the expected marginal utility of consumption.

Graphically, one can see that the value function becomes steeper again leading to a downward kink at $\left(\tilde{a}_{H}, \mathbf{X}\right)$. The proof of my second theorem shows that this is a general property of the problem at hand. The theory characterizes choices in the region where households currently do not participate in the program but are still affected by it. The main insight is that choices are distorted, despite satisfying first order conditions because of the kinks in the expected value function. 
Theorem 2. $\frac{\partial V_{h}(\cdot, \boldsymbol{X})}{\partial k_{h}}=0$ is a necessary condition for $k_{h}(a, \boldsymbol{X})$ to solve (1) and (2) $\forall a_{h+1}(a, \boldsymbol{X})>0$ and $a_{h+1}(a, \boldsymbol{X}) \neq 0$.

The distortions in this region arise because of the life-cycle dimension and stochastic earnings. I begin elaborating on the life-cycle dimension. Consider a household in quarter $H-1$ who has income $E_{H-1}^{\text {gross }} \leq E_{H-1}^{\text {elig }}$. Following the above reasoning, the policy function makes a jump at point $\tilde{a}_{H-1}(\mathbf{X})$. The policy makes a second jump to the right of $\tilde{a}_{H-1}(\mathbf{X})$. Consider the point $\tilde{\tilde{a}}_{H-1}(\mathbf{X})$ s.th. $a_{H-1}\left(\tilde{\tilde{a}}_{H-1}(\mathbf{X}), \mathbf{X}\right)$ is just larger than $\tilde{a}_{H}\left(\mathbf{X}^{\prime}\right)$ for some $\mathbf{X}$ '. Define the objective function:

$$
\begin{aligned}
& W_{H-1}\left(K, \tilde{\tilde{a}}_{H-1}(\mathbf{X}), \mathbf{X}\right)=U\left(\tilde{\tilde{a}}_{H-1}(\mathbf{X})+E_{H-1}^{n e t}-K\right) \\
& +\beta \mathbb{E}\left\{\left(1-\iota_{H-1}\left(\mu_{1}\right)\right) \mathbb{V}_{H-1}\left(a^{\prime}, \mathbf{X}^{\prime}\right)+\iota_{H-1}\left(\mu_{1}\right) \bar{V}\left(a^{\prime}\right)\right\}
\end{aligned}
$$

Figure II (Panel $A$ ) shows the two local maxima of this objective function. The first maximum arises because choosing assets which lead to next period choices in area $B$ of Figure I is relatively unattractive because $V_{H}$ is relatively concave. Hence, some households find it optimal to front-load consumption to today, choose assets just to the left of $\tilde{a}_{H}\left(\mathbf{X}^{\prime}\right)$ and receives means-tested transfers at end of period $H$. There is a second local maximum where the household satisfies the first order conditions again by choosing to the right of $\tilde{a}_{H}\left(\mathbf{X}^{\prime}\right)$ and never participates in the means-tested program. ${ }^{18}$ The policy function makes a second jump at $\tilde{\tilde{a}}_{H-1}(\mathbf{X})$, becomes steeper, and the value function has a second downward kink at this point. I highlight this graphically in Panel $B$.

Similarly, with stochastic earnings, households place positive probability on being eligible for means-testing in the future. Consequently, to smooth consumption better intertemporally, they front-load consumption to today. ${ }^{19}$

\footnotetext{
${ }^{18}$ The figure highlights that non-uniqueness in $k_{h}(a, \mathbf{X})$ can arise when the household is exactly indifferent between choosing to the left and the right of a non-differentiability.

${ }^{19}$ This leads to a rapid increase in the number of non-differentiabilities in the value function because any path of the state variables which makes the household at any point in the future eligible to means-testing has to be considered.
} 
Figure II: Savings Behavior in $H-1$

(A) Objective Function in $H-1$

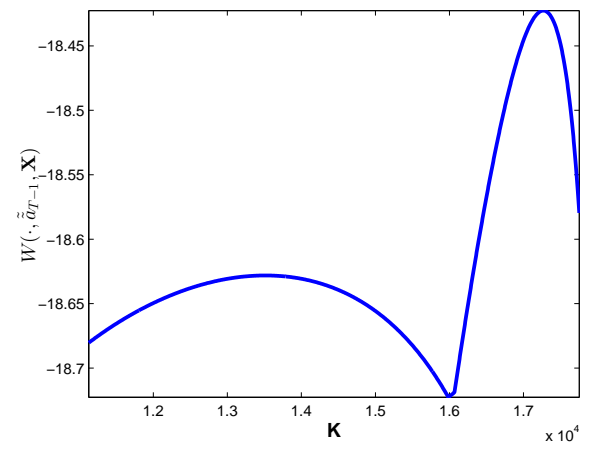

(B) Savings and Value Function in $H-1$

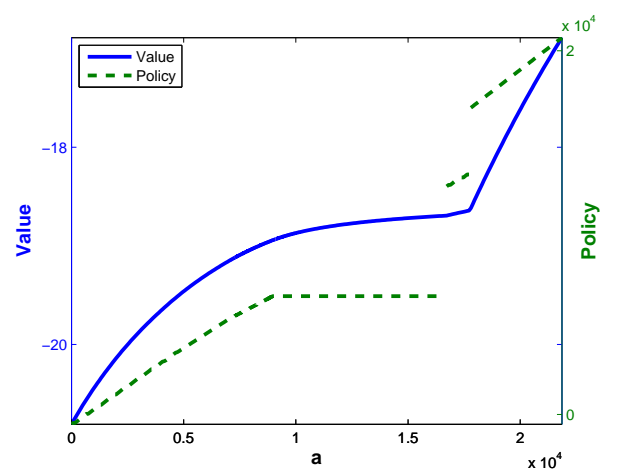

Notes: Panel $A$ displays the objective function in $H-1$, i.e., the objective function from different admissible strategies in $H-1, K_{H-1}$, and following optimal policy in $H$ for an agent choosing between the left and right of a non-differentiable point. Panel $B$ displays the resulting value and policy function. Asset units are expressed in $2004 \$$.

\section{Data Description and Calibration}

The model maps an exogenous income process into households' asset decisions; thereby, into participation in the means-tested program. The calibration strategy targets the earnings uncertainty present in the data. It leaves asset choices untargeted and only uses preference parameters to match averages of households' assets holdings. Table 1 summarizes the calibration.

\subsection{Data Description}

My analysis uses the 1996 (1996-1999), 2001 (2001-2003) and 2004 (20042007) samples from SIPP which is a representative sample of the noninstitutionalized civilian US population maintained by the US Census Bureau. ${ }^{20}$ This sample period features a stable institutional setting. ${ }^{21}$ The SIPP provides monthly information on earnings, transfers from different

\footnotetext{
${ }^{20}$ The 1996 panel oversamples households close to poverty. I use household weights provided by the SIPP in all samples to correct for this issue.

${ }^{21} \mathrm{~A}$ major reform replaced the $A F D C$ program by $T A N F$, as of 1996 . Moreover, it allowed states to harmonize eligibility criteria for major income support programs (categorical eligibility). After the sample period, the 2008 Farm Bill exempts all tax preferred retirement accounts from the means-test for the $S N A P$ from October 2008 onwards. I find it unlikely that households in my data adjusted their savings in anticipation of this bill given that retirement savings are long-term investment decisions.
} 
means-tested programs, out-of-pocket medical expenditure, ${ }^{22}$ wealth, and household affiliation. All data is CPI deflated and convert to 2004 nominal values.

The model is about savings behavior at the household level. I define a household as a group of persons living at a common address, and I define the head as the person in whose name the place is owned or rented. ${ }^{23} \mathrm{I}$ aggregate the data to the model frequency of a quarter. My data counterpart to households' assets in the model is net household's wealth. ${ }^{24}$ This raises the issue how savings which create an income stream late in life should be treated. These savings can be exempt from the means-test when they are not readily available. Individual retirement plans $(I R A)$ and retirement plans of the self-employed (KEOGH) are usually regarded as readily avail$a b l e{ }^{25}$ Moreover, retirement plans managed by the employer (401k plans) are transferred under some conditions into an IRA account in the case of unemployment. Therefore, I treat all these savings as total household wealth which counts against the asset limit.

A household enters the labor-market with age 25 and its economic live ends with age 87 which is the oldest age group the SIPP collects data on. ${ }^{26}$ The median amount of members in households which participate in meanstested programs identifies $N_{h}$. A household has 4 members until age 43, 3 members until age 50, 2 members until age 75, and one member thereafter. The United States Department of Agriculture employs maximum income levels for $S N A P$ based on household size. I assume that their relation reflect the consumption weights $\left(\xi\left(N_{h}\right)\right)$ of households affected by the program. Finally, I aggregate the income and health expenditure data of head and spouse to mimic the within household insurance present in the model.

\footnotetext{
${ }^{22}$ Only available in the 1996 sample.

${ }^{23}$ I change the head of a household when the default head lives non-married in a household together with his parents who have higher earnings and are younger than 67 . Moreover, I define a new household every time when the composition of the household changes.

${ }^{24}$ Savings may not reflect precautionary saving motives or retirement saving decisions, but necessary business equity which a household holds resulting from incomplete markets for business financing. I drop all households holding business equity to account for this latter concern.

${ }^{25}$ The individual states have some freedom in determining which savings are readily available.

${ }^{26}$ I drop observations where the head is school enrolled, or works as a family worker.
} 
All data on income and health expenditures is scaled by $\xi\left(N_{h}\right)$ representing a typical household.

\subsection{Preferences, Employment, and Initial Distribu- tion}

Consistent with Siegel (2002), I set the yearly world interest rate at $4 \%$. To assure that households have on average the amount of self-insurance as in the data, I use the two factors in the utility function, $\beta$ and $\theta_{b}$, to match median wealth holdings. I match medians instead of means, because what matters in my model is the amount of households with low wealth. The welfare implications are relatively insensitive to households with very high wealth holdings which we observe in the data. I use the discount factor $\beta$ to match the median wealth to earnings ratio of households aged younger than 65 , which is 11.63 in my sample. The desire to leave bequests affects the incentives to participate in the means-tested program later in life. Therefore, I use $\theta_{b}$ to match median wealth holdings of households at age 87 . I set $\gamma=1.5$.

Next, let me define employment. I count a household as employed in case this is his predominant status in this quarter. Based on this idea, a household is non-employed whenever his earnings from unemployment are larger than his earnings from work. Moreover, a household is counted as non-employed when his quarterly earnings are less then $\$ 575$, and it reports spending more time in non-employment than in employment during a quarter.

I use annual survival probabilities reported in Bell and Miller (2002) and weight these by education specific probabilities reported in Brown et al. (2008). To calibrate the initial distribution $\left(\lambda_{1}\left(a, \varphi, \mu_{1}, Z\right)\right)$, I use data on households of 25 years of age. The initial non-employment rate for the four education groups is $\left[\begin{array}{llll}0.24 & 0.14 & 0.1 & 0.06\end{array}\right]$. For the employed, I match the densities of wealth holdings for the four education groups in the data. The non-employed, start with the mean amount of assets which I observe in the data for that group. ${ }^{27}$ Note that this calibration does not necessarily

\footnotetext{
${ }^{27}$ Due to the small sample of unemployed, I retain from computing a distribution of asset holdings.
} 
Table 1: Calibration

\begin{tabular}{|c|c|}
\hline Variable & Target/Source \\
\hline$\iota_{h}\left(\mu_{1}\right)$ & Bell and Miller (2002), Brown et al. (2008) \\
\hline$N_{h}$ & Size of participants in data \\
\hline$\xi\left(N_{h}\right)$ & United States Department of Agriculture \\
\hline$r=0.04$ & Siegel (2002) \\
\hline$\beta=0.991$ & Median wealth to earnings ratio of 11.64 \\
\hline$\theta_{b}=44$ & Mean wealth at age 87 \\
\hline$\gamma=1.5$ & \\
\hline$\lambda_{1}\left(a, \varphi, \mu_{1}, Z\right)$ & Distribution of 25 years old in the data \\
\hline $\mathcal{F}\left(\mu_{1}, t\right)$ & Age-earnings profile of education groups \\
\hline$\Pi^{W}, \varphi$ & $\rho=0.96, \sigma=0.007$ \\
\hline$w_{h}^{u}\left(\mu_{1}\right)$ & Mean earnings in non-employment \\
\hline $\mathcal{M}\left(\mu_{h}\right)$ & Mean out-of-pocket medical expenditure \\
\hline$\lambda_{h}$ & Job finding rates by age in data \\
\hline$\delta_{h}$ & Job loss rates by age in data \\
\hline
\end{tabular}

Notes: The left column states the calibrated parameter with its value and the second states the relevant moment. Dollar values are expressed in $2004 \$$.

imply that the amount of bequests left from dying households is the same as households' initial wealth.

\subsection{Employment Transitions, Earnings Process, and Health Expenditures}

Figure III displays the non-employment rate over the life-cycle. Three features stand out. First, high school dropouts have substantially higher non-employment rates early in life. Second, non-employment rises already well before the age of 65 for all groups. Third, a substantial fraction of households still has earnings from employment after the age of 65 . I compute employment transition probabilities conditional on education and five age groups to approximate this profile. ${ }^{28}$ Low educated households have higher non-employment rates, because of higher probabilities entering non-

\footnotetext{
${ }^{28}$ In the data, I find no correlation between wealth holdings and employment status which lends some validity to my assumption for exogenous employment transitions.
} 
Figure III: Non-Employment Rates

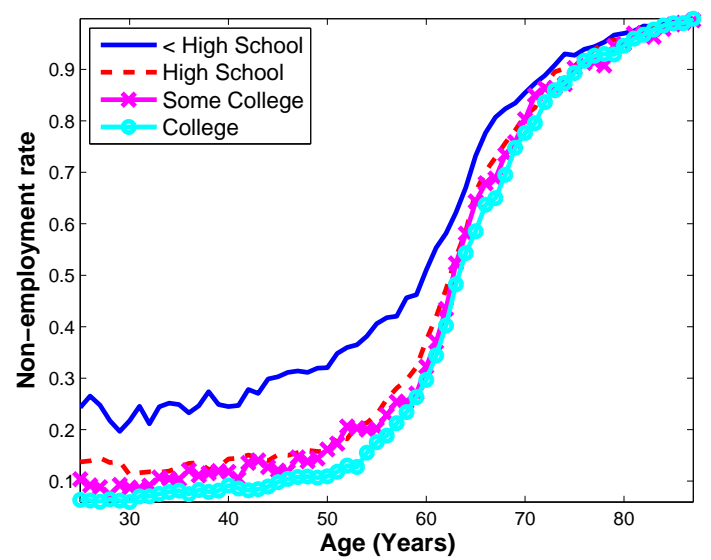

Notes: The figure shows for the four education groups the non-employment rate over the life-cycle.

Source: SIPP (1996, 2001, 2004)

employment, and because they are less likely entering employment again. ${ }^{29}$

Next, I need to estimate the predictable part of life-cycle earnings, the stochastic component, and earnings in non-employment. I postulate the following yearly log earnings process for household $i$ in the data:

$$
\ln \left(w_{i, t}\right)= \begin{cases}\phi_{i}+\Gamma^{w} X_{i, h}+z_{i, h}+\nu_{i, h} & \text { if } h<=H_{160} \\ z_{i, h}=\rho z_{i, h-1}+\epsilon_{i, h} & \\ \phi_{i}+\Gamma^{r} X_{i, h}+z_{i, H_{160}} & \text { if } h>H_{160}\end{cases}
$$

where $\phi_{i}$ is an individual fixed effect, $X_{i, h}$ are education specific age trends, ${ }^{30}$ $\epsilon_{i, h} \sim N\left(0, \sigma^{2}\right)$, and $\nu_{i, h} \sim N\left(0, \sigma_{\nu}^{2}\right)$.

I specify as data counterpart to earnings in the model the sum of earnings from the labor market, incidental earnings, sickness payments, and short-term unemployment compensation. Figure IV shows the predictable part of earnings. The result is smoothed with splines where I allow for

\footnotetext{
${ }^{29}$ The age groups are: $25-34,35-44,45-54,55-64,65-72$, and $73-87$. This implies, in percentage point: $\delta_{h}\left(\mu_{1}^{1}\right)=\left[\begin{array}{llllll}5.6 & 4.8 & 4.5 & 6 & 7.3 & 11.4\end{array}\right], \delta_{h}\left(\mu_{1}^{2}\right)=\left[\begin{array}{llll}3.6 & 2.8 & 2.8 & 4.7\end{array}\right.$

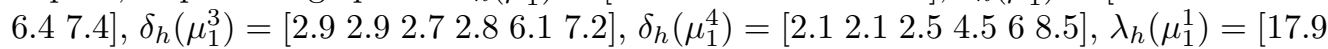
$\left.\begin{array}{lllll}13.6 & 8.1 & 3.6 & 0.7 & 0.1\end{array}\right], \lambda_{h}\left(\mu_{1}^{2}\right)=\left[\begin{array}{llllll}24.1 & 18 & 11.7 & 5.5 & 0.8 & 0.1\end{array}\right], \lambda_{h}\left(\mu_{1}^{3}\right)=\left[\begin{array}{lllll}28.1 & 20 & 13.3 & 6.4 & 0.7\end{array}\right.$

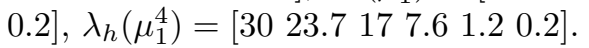

${ }^{30}$ The implicit assumption is that all other changes in worker observables, such as becoming disabled, is an unanticipated earnings shock to the household. Similarly, race and sex are captured by $\phi_{i}$.
} 
(A) Earnings over the Life-cycle

(B) Var of Log Earnings
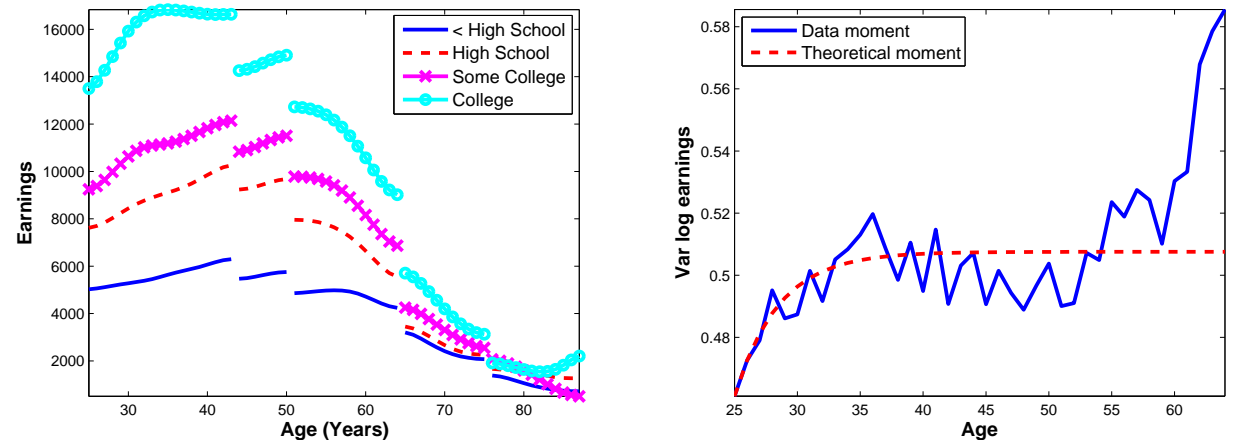

Notes: Panel $A$ shows the estimated earnings growth of households over the life-cycle for four education groups. All data is in 2004 nominal values and household size adjusted. Panel B displays the cross sectional earnings dispersion over age from the data and the theoretical moment (3) for the optimal choice of autocorrelation and variance of earnings shocks.

Source: SIPP (1996, 2001, 2004)

discontinuities whenever household size changes and at age 65 .

To calibrate the stochastic component of earnings, I use the residual earnings $\left(\tilde{w}_{i, h}\right)$. For the mechanics of my model, a key statistic is how the share of income eligible households moves over the life-cycle. Therefore, I opt to identify $\rho$ and $\sigma$ by matching cross sectional earnings dispersion over the life-cycle, as in Storesletten et al. (2004):

$$
\operatorname{Var}\left(\ln \left(w_{i, h}\right)\right)=\sigma_{\phi}^{2}+\sigma_{\nu}^{2}+\sigma^{2} \sum_{s=0}^{h-1} \rho^{2 s}
$$

$\rho$ controls the curvature of the profile and $\sigma$ the increase over time. I match these moments by minimizing the area between the theoretical moment (3) and the earnings residuals estimated from the data:

$$
\min _{\rho, \sigma}\left\{\sum_{25}^{65}\left|\operatorname{Var}\left(\ln \left(w_{i, h}(\rho, \sigma)\right)\right)-\operatorname{Var}\left(\ln \left(\tilde{w}_{i, h}\right)\right)\right|\right\} .
$$

Figure IV (Panel B) plots the data and the resulting profile with $\rho=0.84$ and $\sigma=0.17$. Assuming that the true process is quarterly implies $\rho=0.96$ and $\sigma=0.007$. The theoretical moment does a good job matching the data until age 57 , but implies too little earnings inequality thereafter. Following Tauchen (1986), I use the entries of the vector of values and the transition matrix of a $N=7$ states Markove process to match the moments of the 
Figure V: Earnings in Non-Employment and Health Expenditures

(A) Earnings During

Non-Employment

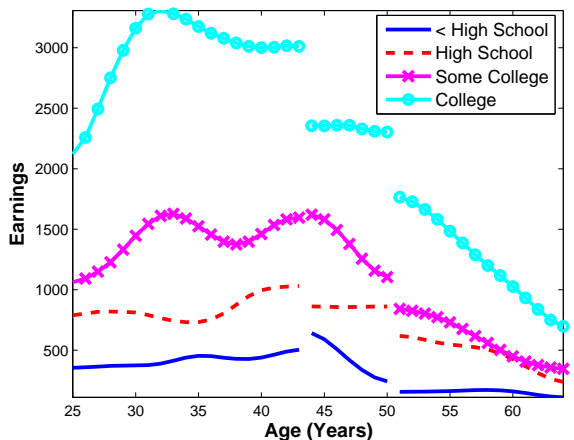

(B) Heath Expenditures in Old Age

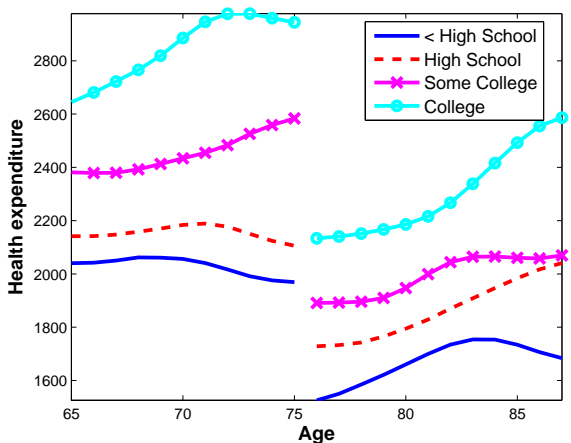

Notes: Panel A display labor market earnings during non-employment for the four education groups. Panel $B$ shows the estimated health expenditure for four education groups. All data is in 2004 nominal values and household size adjusted.

Source: SIPP (1996, 2001, 2004)

$A R(1)$ process. $^{31}$ In the first period, households draw a value to replicate the within education earnings dispersion from the data at age 25 .

Figure $\mathrm{V}$ shows the mean earnings until age 65 of those non-employed by education group which identifies $w_{h}^{u}$. Finally, I need to parametrize the amount of medical expenditures that households incur during old age. Following a similar idea as with households earnings, I regress out-of-pocket medical expenditures on education specific age profiles and apply spline smoothing afterward. Figure V shows that households with higher education have higher out-of-pocket medical expenditures.

\section{Comparing Implications of the Model with the Data}

This section shows that the model maps the calibrated exogenous earnings process into wealth outcomes which are similar to the data. In the model, wealth is the only means of self-insurance for a household. In the data, there may be other means, such as the extended family. Reassuring, in a second step, this section shows that the model maps the wealth outcomes

\footnotetext{
${ }^{31}$ The reason for the relatively low number of earnings states is the computational burden.
} 
Figure VI: Comparing Model and Data

(A) Participation in Means-Testing

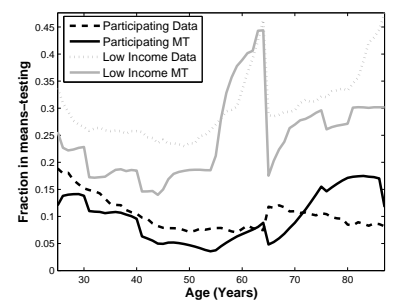

(B) Share of Households with low Wealth

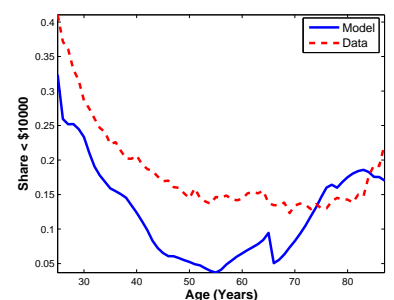

(C) Median Wealth by Education

Notes: Panel A displays the fraction of households which participates in means-tested programs. Data refers to SIPP households which participate in income support programs. MT refers to the model. The gray lines show the fraction of households which has earnings below the eligibility threshold in the model. Panel $B$ shows the fraction of households with less than $\$ 10000$. Panel $C$ displays median wealth holding of high school dropouts and college graduates in the data and the model. Asset units are expressed in $2004 \$$.

into consumption responses upon earnings shocks which are consistent with stylized facts from the data.

Figure VI (Panel A) displays the share of households which would be eligible for the program due to sufficient low earnings in the model. The figure already highlights that the earnings process is not rich enough compared to the data. Particularly, the approximation is underpredicting the share of low income prime aged households. Nevertheless, the model is quite successful in mapping the income process into a household decision to participate in the means-tested program. The model matches the overall mean and the decreasing profile over the working life. However, it predicts a too steep rise of participation rates of the elderly.

The share of prime aged households with low income decreases more slowly than the share of households actually receiving transfers. Put differently, less low earning households satisfy the means-test. Panel $B$ compares the fraction of households with relatively few assets, less than $\$ 10000$, in the model to the data. The model replicates the downward sloping profile for prime aged households; yet, it is somewhat too pronounced. Households build up wealth for retirement savings and assets for bequests. Nevertheless, a characteristic feature of data and model is a large fraction of households which holds little assets throughout all stages of the life-cycle. ${ }^{32}$

\footnotetext{
${ }^{32}$ The model of Hubbard et al. $(1994,1995)$ matches even better the share of low wealth households. Allowing for a positive means-test instead of a consumption floor and introducing a bequest motive significantly reduces the distortions of the means-test.
} 
Table 2: Insurance against Earnings Shocks

\begin{tabular}{l}
\hline \hline $\begin{array}{c}\text { \% of unemployed } \\
\text { With low wealth }\end{array}$ \\
\cline { 2 - 3 }
\end{tabular}

Panel $C$ shows that in the model and data these tend to be households with low education. Households with higher education find it more unlikely to ever pass the earnings test of the insurance program. Consequently, they do not adjust their assets as strongly as a response to the means-test. The result is a large wealth inequality between education groups. Compared to the data, both median wealth profiles peak too early in the model.

So far, I compared aggregate wealth outcomes from the model to the data. Earlier literature has studied whether households savings decisions on the micro level are affected by means-tested programs. Appendix D shows that the model is able to match several of these reduced form estimates. Particularly, it is consistent with a statistically significant increase of savings of young households in response to a rise in the asset threshold (see Powers, 1998), but an insignificant response for prime aged households to a similar rise (see Hurst and Ziliak, 2006). To understand the latter, note that households may not raise their wealth in response to looser asset testing because such a reform effectively expands insurance; thus, lowers precautionary savings. Moreover, households which prior to the reform did not participate in the program because of too high wealth, may want to participate with higher thresholds and start decumulating wealth. The model is also consistent with small total wealth responses of likely participants as a response to a rise in means-tested transfers (see Neumark and Powers, 1998; Ziliak, 2003).

To understand the effects of means-testing on social welfare, we need to understand how ultimately consumption is affected by earnings shocks. 
Table 2 shows that in the data, $33 \%$ of households entering unemployment have wealth below $\$ 10000 .{ }^{33}$ Carroll et al. (2003) show that particularly households with low education suffer from low precautionary savings in US data. I compare this statistic to prime aged households in the model. $11.6 \%$ of households have such low wealth holdings upon non-employment, and these are mostly households with low education. Because of the low wealth holdings, households decrease their consumption upon non-employment on average by $5.6 \%$, which is close to the $6.8 \%$ of food consumption reported by Gruber (1997). Blundell et al. (2008) show that durable consumption responds stronger than food consumption. With this adjustment, the decrease in the data is $8 \%$.

Non-employment is just one type of shock to households' earnings. Blundell et al. (2008) report the amount of consumption changes resulting from permanent shocks to household income. One of their findings is that households with college education are twice as good insured against permanent income shocks compared to households without college education. Table 2 shows that the model implies a factor of 1.5. One difference between the model and data is that the former implies more consumption insurance compared to the data in both cases, possibly reflecting the assumption that shocks to earnings are not permanent in the model.

\section{$5 \quad$ Welfare Analysis}

This section discusses the welfare implications of the asset means-test. The idea of the policy experiment is that households born after a particular data are no longer subject to the means-test, but all income thresholds $\left(E_{h}^{\text {elig }}\right)$ are unchanged. The welfare measure is based on a comparison of two cohorts being born under the different policies. I express welfare as the willingness of an unborn to forgo lifetime earnings. Define by $\mathbb{L}\left(E_{1: H}^{n e t}\right)$ the expected value of a household born into the baseline policy, and facing the expected net earnings stream $E_{1: H}^{n e t}$ over its life-cycle. This is simply integrating the

\footnotetext{
${ }^{33}$ See Gruber (2001) for similar results. A difference between the model and the data is that a substantial larger fraction of households holds zero wealth in the data.
} 
value function over the initial distribution of households:

$$
\mathbb{L}\left(E_{1: H}^{n e t}\right)=\int V_{1}(a, \mathbf{X}) d \lambda_{1}(a, \mathbf{X})
$$

Let the expected value of a household born into the new legislation and facing the same expected earnings stream and initial conditions be denoted by $\mathbb{M}\left(E_{1: H}^{n e t}\right) .{ }^{34}$ The fraction of earnings which makes such a household indifferent between the two regimes, $\omega$, solves:

$$
\mathbb{L}\left(E_{1: H}^{n e t}\right)=\mathbb{M}\left(\omega E_{1: H}^{n e t}\right)
$$

The model environment implies that full insurance is optimal from a perspective of an unborn household. Because the baseline model is away from first best, I study reforms which keep the total value or resources needed to finance the system constant. Put differently, I do not address the question whether the level of current governmental insurance is optimal, but whether changing asset means-testing increases social welfare given the same amount of expenditures. My framework also implies that households desire full insurance against education draws. To eliminate this effect, Section 5.1 studies reforms which pay to each education group the same amount of transfers as before the reform, but independent of the assets of individual households. Section 5.2 extends the analysis to reforms which allow for redistribution of transfers across education groups.

\subsection{Education Contingent Transfers}

The section shows the welfare consequences of abolishing the means-test of $\$ 5000$. It quantifies the different insurance mechanisms of means-testing and decomposes the welfare effects into the four different education groups. Finally, it computes the asset limit with the largest welfare gains and demonstrates interaction effects between means-tested and non-means-tested insurance programs.

\footnotetext{
${ }^{34}$ Wealth holdings at death are higher without a means-test. Allowing for differences in intergenerational transfers makes a non-means-tested policy substantially more attractive.
} 


\subsubsection{Abolishing the Means-Test}

The top panel of Table 3 shows that an unborn household is willing to pay 0.26 percent of life-time earnings to not abolish the means-test of $\$ 5000$. Put differently, for an unborn household, the insurance effects of the meanstest outweigh its adverse incentive effects. The means-test has three positive insurance mechanisms. First, it provides relatively high transfers to those with the highest utility gains. Second, young households have relatively many household members and expected positive earnings growth. Thus, the planner would like to allocate higher transfers to these households than to an elderly household with low earnings. Because young households have lower wealth than elderly households, the means-test achieves exactly this. Third, as households run down assets only after repeatedly poor labor market outcomes, the means-test allows for better insurance after persistently poor labor market outcomes, instead of transitory earnings losses. In that sense, it serves as partial substitute for history dependent taxation.

To quantify these different mechanisms, the lower panel of Table 3 displays the welfare outcomes from reforms which shut them down sequentially. The first reform assures that transfers to a group of households are the same after the reform conditional on education and age, i.e., the state vector $\left(h, \mu_{1}\right)$. In this case, an unborn household is willing to forgo 0.04 percent of life-time earnings to abolish the means-test. The second reform, additional to age, also conditions on the persistent earnings state, i.e., the state vector $(h, \mathbf{X})$. Now, an unborn is willing to forgo 0.16 percent of lifetime earnings to abolish the means-test.

Table 3 also shows that high school dropouts are willing to forgo 5.6 percent of life-time earnings to conduct the reform. Contrary, households with higher education benefit from the means-test. To understand the heterogeneous effects, Table 4 compares the consumption responses and average wealth holdings of high school dropouts and college graduates upon earnings shocks. High school dropouts adjust their savings decisions strongly when faced by the asset means-test. Consequently, they have no means of self-insurance against poor labor-market outcomes and behave similar to hand-to-mouth consumers. Consumption declines by $8.14 \%$ when these households become non-employed. Consumption is down by $18.72 \%$ rela- 


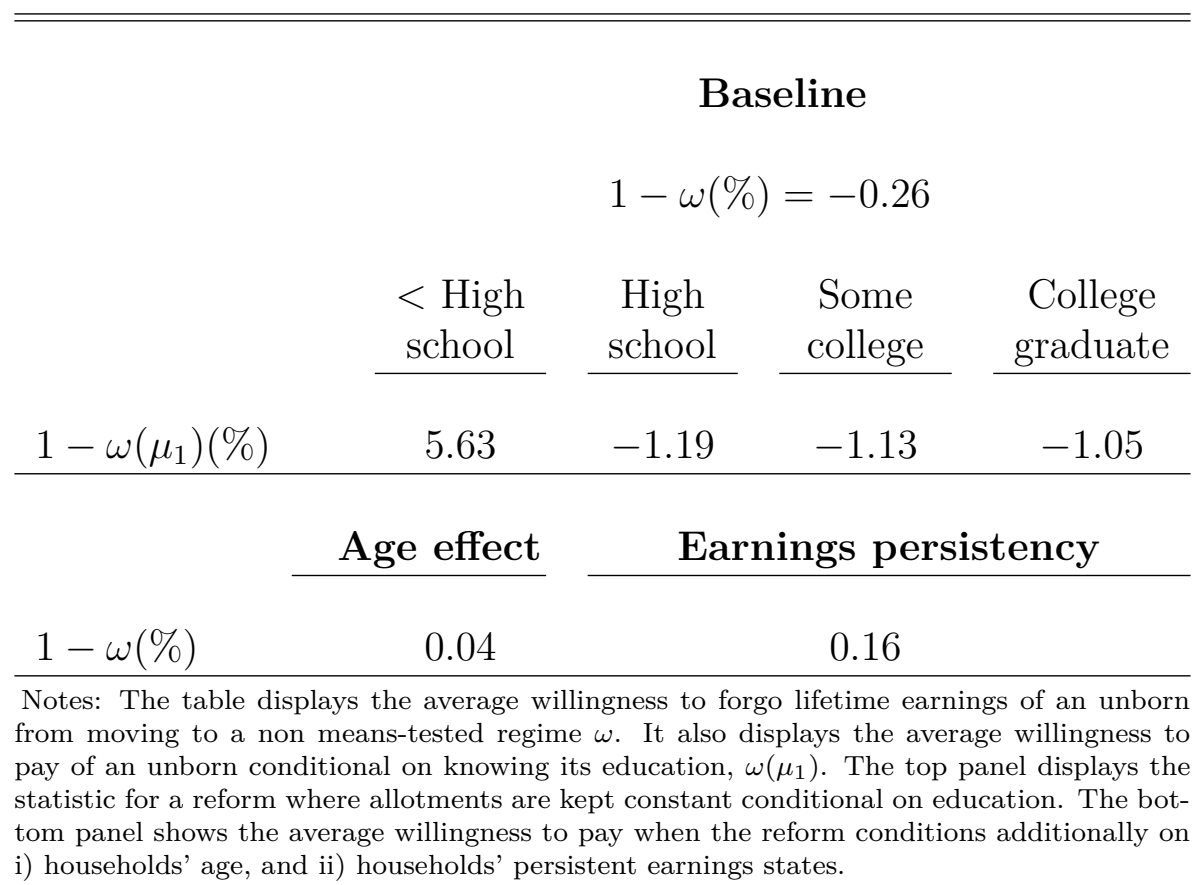

tive to the last employment quarter after three quarters of non-employment. In contrast, these households are successful to smooth consumption after non-employment shocks without the means-test. The consumption drop after three periods in non-employment is more than 2 times smaller. The reason is that high school dropouts enter non-employment on average with two times more assets which allows them to almost sustain their consumption level despite lower allotments. Seemingly contradictionary, households react stronger to persistent earnings shocks without the means-test, despite less self-insurance. The reason is that with the means-test, a negative shock to persistent earnings may actually lead households to consume more, because they want to become eligible for the means-tested program.

Upper earnings groups need to be in a relatively low earnings state to become eligible. Therefore, their savings are less affected by the means-test and they deplete their savings only in the case of repeatedly poor labormarket outcomes. In this case, they gain from the relatively generous transfers. This can also be seen in Table 4. Households with a completed college degree reduce consumption on average by $7.38 \%$ when becoming unemployed in the non-means-tested regime, but they reduce it only by 
Table 4: Wealth Levels and Consumption Response after Earnings Shocks

\begin{tabular}{|c|c|c|c|c|c|c|}
\hline & \multicolumn{2}{|c|}{$\begin{array}{l}\text { Non-emp- } \\
\text { loyment }\end{array}$} & \multicolumn{2}{|c|}{$\begin{array}{c}3 \text { Quarters of } \\
\text { non-employment }\end{array}$} & \multicolumn{2}{|c|}{$\begin{array}{l}\text { Persistent } \\
\text { Earnings }\end{array}$} \\
\hline & $\begin{array}{l}\% c \\
\text { drop }\end{array}$ & $\begin{array}{l}\text { Wealth } \\
\text { in } 1000\end{array}$ & $\begin{array}{l}\% c \\
\text { drop }\end{array}$ & $\begin{array}{l}\text { Wealth } \\
\text { in } 1000\end{array}$ & $\begin{array}{l}\% \text { passed } \\
\text { to } c\end{array}$ & $\begin{array}{l}\text { Wealth } \\
\text { in } 1000\end{array}$ \\
\hline \multicolumn{7}{|c|}{ Means-Tested } \\
\hline$<\mathrm{HS}$ & 8.14 & 32 & 18.72 & 33 & 2.47 & 29 \\
\hline $\mathrm{C}$ & 6.56 & 244 & 9.74 & 247 & 1.61 & 232 \\
\hline \multicolumn{7}{|c|}{ Non-Means-Tested } \\
\hline$<\mathrm{HS}$ & 7.05 & 77 & 8.94 & 81 & 10.21 & 79 \\
\hline $\mathrm{C}$ & 7.38 & 257 & 10.61 & 261 & 6.05 & 244 \\
\hline
\end{tabular}

Notes: The table displays the beginning of period mean wealth and consumption adjustments after poor labor-market outcomes for high school dropouts $<H S$ and college graduates $C$. The top panel displays the results under the means-tested regime, and the lower panel shows the same for the nonmeans-tested regime. Wealth units are expressed in $2004 \$$.

$6.56 \%$ under means-testing. The insurance effect for persistent shocks to earnings is even larger. This occurs, despite that these households hold lower average assets under means-testing. Particularly early in life, these households gain from the means-test. The higher insurance implies that these households need to build up less precautionary savings which brings their consumption closer to the social planer solution.

\subsubsection{Asset Limits and Interactions with Other Insurance Pro- grams}

The heterogeneous wealth holdings of different education groups suggest that altering asset limits may improve welfare. To investigate this, I study reform which abolish the means-test given different asset limits. As before, the comparison is with a regime without the means-test but constant 
Table 5: Changing the Welfare-State

\begin{tabular}{l}
\hline \hline \begin{tabular}{l}
\hline \\
\hline
\end{tabular}$(\$ 1000)$ \\
\end{tabular}

total transfers conditional on households' education. ${ }^{35}$ The top panel of Table 5 shows the average willingness to pay for the reform. For very low asset limits, abolishing the means-test creates welfare gains. With higher thresholds, a means-tested regime becomes more desirable relative to a non-means-tested regime. Compared to a regime without a means-test, welfare gains are largest with $\bar{a}=145000$. An unborn household is willing to forgo more than one percent of life-time earnings to not abolish the means-test. The high asset thresholds imply almost no distortionary effects for high school dropouts. At the same time, they allow for higher allotments to households in need because households with high assets which become temporarily non-employed receive no transfers.

Low et al. (2010) show that the value of unemployment insurance is limited in a life-cycle model without a means-test in income support programs. Because unemployment risk is temporary, households have little problems accumulating sufficient assets for self-insurance. As shown above, high school dropouts may fail doing so when some income support programs are means-tested. The bottom panel displays the welfare effects of abolishing the means-test when unemployment benefit compensation to low income households is lower. The experiment reduces the replacement rate of unemployment compensation to the replacement rate of the top income households. For low earnings households, this implies a reduction from 53

\footnotetext{
${ }^{35}$ Note that the reform keeps total governmental expenditure constant. However, the size of the government varies between economies with different asset thresholds.
} 
to 13 percent. The welfare losses from abolishing the means-test fall to 0.15 percent of lifetime earnings compared to 0.26 present in the baseline specification. The table also shows the welfare effects of abolishing the means-test when the replacement rate from Social Security to all households is reduced to the replacement rate of the highest earnings households (30 percent). In this case, the losses of abolishing the means-test fall to 0.22 percent of lifetime earnings. Resulting from the means-test, some of the low earnings households build up little savings for retirement. When social security replaces less of income, these households have to downward adjust their consumption upon retirement. Summing up, from an insurance perspective, the government should either use a means-test coupled with strong insurance against temporary earnings risk and predictable earnings changes for low income households, or have weak insurance against temporary risk and predictable earnings changes but no means-test.

\subsection{Distributional Effects of Means-Testing}

The political discussion about means-testing is mostly centered around the possibility of households to respond to shocks. Yet, a reform of the means-test may have consequences of how resources are distributed across education groups. To address this, I study a reform which achieves constant expenditures by cutting benefits proportional to all households. An unborn household is willing to pay 1.57 percent of life-time earnings to not abolish the means-test.

To understand the large welfare loses, note that the reform allocates transfers away from those households with low education. They have the lowest wealth; therefore, receive the most transfers under means-testing. Without the means-test, high educated households which face temporary non-employment spells start receiving transfers. Thus, to achieve the gains from loosening the means-test, the government has to counteract these redistributional forces by granting more transfers to the low educated, possibly through the tax schedule. 


\section{Conclusion}

This paper computes the asset limit for US means-tested income support programs which minimizes consumption volatility of households. To this end, it builds an incomplete markets life-cycle model with large nonemployment shocks and persistent earnings risk. The optimal policy has to weigh the savings distortions inflicted by the means-test against its positive insurance mechanisms. To quantify these effects, the paper studies the willingness to pay of an unborn household for an expenditure neutral reform which abolishes the means-test of $\$ 5000$; a common threshold across US states at the beginning of the century. A means-test assures that those households receive transfers which have the largest utility gains from extra consumption. This insurance mechanism is slightly dominated by the savings distortions from the perspective of an unborn household. A means-test also allocates relatively more transfers to young households which benefit more from these transfers more than elderly households. An unborn household is willing to pay 0.3 percent of life-time consumption for this mechanism. Finally, a means-test allocates more transfers to persistently low earnings relatively to temporary low earnings. An unborn household is willing to pay 0.12 percent of life-time earnings for this latter mechanism. In total, an unborn household is willing to pay 0.26 percent of life-time earnings to have a means-test of $\$ 5000$.

The gains of means-testing are not evenly distributed in the population. Households with low education reduce their asset accumulation strongly in face of the means-test. They have little self-insurance against earnings risk and suffer from high consumption volatility. As a result, these households are in favor of abolishing it. Households with higher education adjust their savings less when faced by the means-test. As a result, they gain from it because of better insurance. An asset threshold of $\$ 145000$ optimally balances these opposing forces and implies large welfare gains above a nonmeans-tested policy; an unborn household is willing to forgo more than 1 percent of lifetime earnings to not abolish the means-test.

There are several possible avenues of extending the analysis presented in this paper. The present paper focuses on persistent and transitory earnings risk. Yet, there are other risks households face. Braun et al. (2013) 
study the means-test of Medicaid in old age. Health expenditure shocks are large, rare, and strongly depend on age. This might reduces the distortions on savings decisions during working life relative to the persistent earnings shocks. Regarding the exogeneity assumption of earnings, there may be important interactions between the asset means-test and employment choices. Households with low wealth and low labor-market earnings may select themselves into unemployment, but high wealth households may choose to continue to work. Similarly, entering into retirement is an endogenous decision possibly affected by households wealth levels; hence, by the presence of the means-test. 
Table 6: Social Security

\begin{tabular}{lc}
$\begin{array}{c}\text { Pre Retirement } \\
\text { Earnings }\end{array}$ & $\begin{array}{c}\text { Replacement } \\
\text { Rate }\end{array}$ \\
$\$ 33915$ & 0.56 \\
$\$ 8700$ & 0.42 \\
$\$ 18484$ & 0.3 \\
\hline $\begin{array}{l}\text { Notes: The table shows for different levels of pre } \\
\text { retirement quarterly earnings the replacement rate } \\
\text { from social security. }\end{array}$
\end{tabular}

\section{A Non Means-Tested Insurance}

Table 6 provides the replacement rates for social security. I take the data from Social Security Administration (2004). I linearly interpolate the values for my model simulation. To obtain the amount of pensions, I compute the distribution of households over $\varphi$ conditional on education in the model at age $H_{160}$. By assumption, this distribution does not change up to terminal age $H$. In the data, I compute the distribution of pension payments conditional on age. Because pension payments depend only on the last realization of $\varphi$ in the model, I can match the distribution of payments in the data to the distribution of households in the model.

The unemployment insurance scheme is supposed to mimic the average insurance available to households in the data. I set $\nu$ to the average replacement rate across US states reported by Meyer (2002) and $b^{\max }$ to the average maximum. Finally, I use Figure 1 from Golosov and Sargent (2012) to compute the income tax code. Importantly, the figure includes earned income tax credits for low earning households. Again, linear interpolation provides values for missing observations.

\section{B Computing Means-Tested Transfers}

This section outlines the amount of transfers households receive from different programs. Table 7 provides the maximum amount of transfers households may receive over their life-cycle.

When eligible to $S N A P$, the maximum amount of benefits is $\overline{T R}_{h}^{F}$. Fol- 


\begin{tabular}{|c|c|}
\hline Variable & Target/Source \\
\hline$\overline{T R}_{h}^{F}=\$\left[\begin{array}{llll}1413 & 1113 & 777 & 423\end{array}\right]$ & Federal Legislation \\
\hline$\overline{T R}^{T}=\$ 1347$ & Mean in Kassabian et al. (2011) \\
\hline$\overline{T R}_{W}=\$ 135$ & Mean in the Data \\
\hline$\overline{T R}_{W}^{L}=\$ 501$ & Mean in the Data \\
\hline$\overline{T R}_{R}^{L}=\$ 317$ & Mean in the Data \\
\hline$\overline{T R}_{h}^{S}=\$\left[\begin{array}{lll}2538 & 1692\end{array}\right]$ & Federal Legislation \\
\hline
\end{tabular}

Notes: The left column states the calibrated variable with its value and the second states the relevant moment. "Data" refers to my SIPP sample. Dollar values are expressed in $2004 \$$.

lowing US federal legislation, total amount of transfers to an eligible household is:

$$
T R_{h}^{F}=\max \left\{\overline{T R}_{h}^{F}-0.3\left(0.8 w_{h}^{\text {gross }}-d\right)\right\} .
$$

where $d$ is a cash deductible.

Denote by $\overline{T R}^{T}$ the maximum amount of receivable benefits from TANF. Following legislation in most US sates, total transfers are given by

$$
T R^{T}=\max \left\{\overline{T R}^{T}-0.8 w_{h}^{\text {gross }}, 0\right\}
$$

SSI deducts income from the maximum allotment $\overline{T R}_{h}^{S}$ according to:

$$
T R_{h}^{S}=\max \left\{\overline{T R}_{h}^{S}-\left[w_{h}^{\text {gross }}-\left[\left(w_{h}^{\text {gross }}-d_{r}\right) / 2+d_{r}\right]\right], 0\right\},
$$

where $d_{r}$ is a cash deductible.

\section{Proofs}

This section provides proves for the theories laid out in the main part of the paper. To keep notation simple, I sometimes focus on the current state of being employed. Moreover, to make the notation more compact define 
conditional on the employment state, e.g., E:

$$
\begin{aligned}
\mathbb{V}_{h+1}\left(a^{\prime}, \mathbf{X}^{\prime}\right)=\mathbb{E}_{h}\left\{( 1 - \iota _ { h } ( \mu _ { 1 } ) ) \left[\left(1-\delta_{h}\left(\mu_{1}\right)\right) V_{h+1}\left(a^{\prime}, \varphi^{\prime}, \mu_{1}, E\right)\right.\right. \\
\left.\left.+\delta_{h}\left(\mu_{1}\right) V_{h+1}\left(a^{\prime}, \varphi^{\prime}, \mu_{1}, U b\right)\right]+\iota_{h}\left(\mu_{1}\right) \bar{V}\left(a^{\prime}\right)\right\}
\end{aligned}
$$

Moreover, define the law of motion for assets induced by the end of period choice $k$ as

$$
\phi(k)=(1+r) k+T R\left(k, E_{h}^{g r o s s}, h\right)
$$

Proof of Theorem 1: I first show that $V_{h}(\cdot, \mathbf{X})$ is strictly increasing. Let $k_{h}\left(a^{j}, \mathbf{X}\right)$ be the optimal policy and let $a^{k}>a^{j}$. By the definition of $\Gamma, \mathrm{I}$ have $\Gamma^{j} \subset \Gamma^{k}$. Thus, $k_{h}\left(a^{j}, \mathbf{X}\right)$ is an admissible policy for $a^{k}$ with strictly larger current consume this period. Because $U$ is increasing in current consumption and $k_{h}(a, \mathbf{X})$ maximizes $V_{h}, V_{h}\left(a^{k}, \mathbf{X}\right)>V_{h}\left(a^{j}, \mathbf{X}\right)$.

Now assume that the optimal policy is such that $k_{h}\left(a^{j}, \mathbf{X}\right)>k_{h}\left(a^{k}, \mathbf{X}\right)$. It directly follows for the transfer induced by point $a^{k}: T R^{k} \geq T R^{j}$. First, assume they are equal. Because $V(\cdot, \mathbf{X})$ is strictly increasing, I have $\mathbb{V}_{h+1}\left(\phi\left(k_{h}\left(a^{j}, \mathbf{X}\right)\right), \mathbf{X}^{\prime}\right)>\mathbb{V}_{h+1}\left(\phi\left(k_{h}\left(a^{k}, \mathbf{X}\right)\right), \mathbf{X}^{\prime}\right)$. Resulting from the concavity of $U, k_{h}\left(a^{k}, \mathbf{X}\right)$ cannot be optimal given the optimality of $k_{h}\left(a^{j}, \mathbf{X}\right)$. Assume now $T R^{k}>T R^{j}$. Hence, $T R^{j}=0$ and $T R^{k}>0$. This again contradicts the concavity of $U$ because the marginal gain from consuming more today are larger for the lower asset position.

I now turn to the second part of the theorem. The proof goes by contradiction. $k_{h}(a, \mathbf{X})$ would be strictly increasing when $\exists$ a point $\left(\hat{a}_{h}-\epsilon, \mathbf{X}\right)$ s.th. $k_{h}\left(\hat{a}_{h}-\epsilon, \mathbf{X}\right)=\frac{\bar{a}}{1+r}$ and $\forall \epsilon$ the point $\left(\hat{a}_{h}, \mathbf{X}\right)$ leads to $k_{h}\left(\hat{a}_{h}, \mathbf{X}\right)>\frac{\bar{a}}{1+r}$. Moreover, $\operatorname{TR}\left(k_{h}\left(\hat{a}_{h}-\epsilon, E_{h}^{\text {gross }}, h\right)>0=T R^{+}\right.$and $T R\left(k_{h}\left(\hat{a}_{h}, E_{h}^{\text {gross }}, h\right)=\right.$ 0 . I now show that for this case $k_{h}\left(\hat{a}_{h}, \mathbf{X}\right)>\frac{\bar{a}}{1+r}$ cannot be an optimal policy $\forall \epsilon$. The policy $\tilde{k}_{h}\left(\hat{a}_{h}, \mathbf{X}\right)=\frac{\bar{a}}{1+r}$ was preferred iff $\exists$ an $\epsilon$ s.th.

$$
\begin{aligned}
\underbrace{U\left(\hat{a}_{h}+E_{h}^{n e t}-k_{h}\left(\hat{a}_{h}, \mathbf{X}\right)\right)-U\left(\hat{a}_{h}+E_{h}^{n e t}-\tilde{k}_{h}\left(\hat{a}_{h}, \mathbf{X}\right)+\epsilon\right)}_{<0} \\
<\underbrace{\beta\left[\mathbb{V}_{h+1}\left((1+r)\left[k_{h}-\epsilon\right]+T R^{+}, \mathbf{X}^{\prime}\right)-\mathbb{V}_{h+1}\left((1+r) k_{h}, \mathbf{X}^{\prime}\right)\right]}_{>0},
\end{aligned}
$$


where the inequality on the right hand side comes from the fact that $V_{h+1}$ is increasing in $a$ and $T R^{+}>0$.

For the third part of the theorem, assume $\forall a, k_{h}(a, \mathbf{X}) \leq \frac{\bar{a}}{1+r}$. For expositional reasons, I assume the equality holds. Now consider the alternative policy $k_{h}\left(a^{0}, \mathbf{X}\right)=\frac{\bar{a}+x}{1+r}$ for some state $(a, \mathbf{X})$ and $x>T R\left(k_{h}, E_{h}^{\text {gross }}, h\right)$. This alternative policy is better iff the following inequality holds:

$$
\begin{aligned}
& \underbrace{U\left(a+E_{h}^{n e t}-\frac{\bar{a}}{1+r}\right)-U\left(a+E_{h}^{\text {net }}-\frac{\bar{a}+x}{1+r}\right)}_{>0} \\
&<\underbrace{\beta\left[\mathbb{V}_{h+1}\left(\bar{a}+x, \mathbf{X}^{\prime}\right)-\mathbb{V}_{h+1}\left(\bar{a}+T R\left(k, E_{h}^{\text {gross }}, h\right), \mathbf{X}^{\prime}\right)\right]}_{>0 \text { for } a \text { large enough }} .
\end{aligned}
$$

The convergence to 0 of the left hand side results from the concavity of $U$ and the inequality on the right hand side results from an increasing value function.

Proof of Theorem 2: Clausen and Strub (2012) show that non-differentiable points can be classified into upward, the function is not sub-differentiable, and downward kinks, the function is not superdifferentiable. As they demonstrate, choosing $k_{h}$ at a downward kink cannot be optimal because the slope of $V_{h}(\cdot, \mathbf{X})$ is increasing to the right. Therefore, it is sufficient for me to show that all points of discontinuity of $V_{h}(\cdot, \mathbf{X})$ are downward kinks or equivalently that $V_{h}$ is sub-differentiable. Following the notation of Clausen and Strub (2012), call $\partial_{D} V_{h}\left(a^{0}, \mathbf{X}\right)$ the sub-differentiable of $V_{h}$ at $a^{0}$ :

$$
\begin{array}{r}
\partial_{D} V_{h}\left(a^{0}, \mathbf{X}\right)=\left\{m \in \Re: \lim _{\substack{\Delta a^{0} \rightarrow 0^{-} \\
\sup }}\left\{\frac{V_{h}\left(a^{0}+\Delta a^{0}, \mathbf{X}\right)-V_{h}\left(a^{0}, \mathbf{X}\right)}{\Delta a^{0}}\right\} \leq m\right. \\
\left.\leq \liminf _{\Delta a^{0} \rightarrow 0^{+}}\left\{\frac{V_{h}\left(a^{0}+\Delta a^{0}, \mathbf{X}\right)-V_{h}\left(a^{0}, \mathbf{X}\right)}{\Delta a^{0}}\right\}\right\} .
\end{array}
$$

$V_{h}\left(a^{0}, \mathbf{X}\right)$ is sub-differentiable at $a^{0}$ iff $\partial_{D} V_{h}\left(a^{0}, \mathbf{X}\right)$ is non-empty. Intuitively, a function is sub-differentiable at a point when its slope approaching the point from the right is larger than the slope approaching from the left. 
I first show that the upward jump in the policy function at $\tilde{a}_{h}(\mathbf{X})$ leads to $V_{h}$ being still sub-differentiable. For the ease of presentation, I omit the dependence of $\tilde{a}_{h}$ on the exogenous state vector $\mathbf{X}$ from here on. Theorem 1 establishes that $k_{h}\left(\tilde{a}_{h}, \mathbf{X}\right)=k_{h}\left(\tilde{a}_{h}-\epsilon, \mathbf{X}\right)=\tilde{k}$. Therefore, the first part of (5) simplifies to

$$
\limsup _{\Delta \tilde{a}_{h} \rightarrow 0^{-}}\left\{\frac{U\left(\tilde{a}_{h}+\Delta \tilde{a}_{h}+E_{h}^{n e t}-\tilde{k}\right)-U\left(\tilde{a}_{h}+E_{h}^{n e t}-\tilde{k}\right)}{\Delta \tilde{a}_{h}}\right\} .
$$

The second part of (5) becomes

$$
\begin{aligned}
\liminf _{\Delta \tilde{a}_{h} \rightarrow 0^{+}}\left\{\frac{U\left(\tilde{a}_{h}+\Delta \tilde{a}_{h}+E_{h}^{n e t}-k_{h}\left(\tilde{a}_{h}+\Delta \tilde{a}_{h}, \mathbf{X}\right)\right)}{\Delta \tilde{a}_{h}}\right. & -\frac{U\left(\tilde{a}_{h}+E_{h}^{n e t}-\tilde{k}\right)}{\Delta \tilde{a}_{h}} \\
+\beta\left[\frac{\mathbb{V}_{h+1}\left((1+r) k_{h}\left(\tilde{a}_{h}+\Delta \tilde{a}_{h}, \mathbf{X}\right), \mathbf{X}^{\prime}\right)}{\Delta \tilde{a}_{h}}\right] & \left.\left.-\frac{\mathbb{V}_{h+1}\left((1+r) \tilde{k}, \mathbf{X}^{\prime}\right)}{\Delta \tilde{a}_{h}}\right]\right\} .
\end{aligned}
$$

Because $k_{h}\left(\tilde{a}_{h}+\Delta \tilde{a}_{h}, \mathbf{X}\right)$ is optimal, it must be that

$$
\begin{aligned}
& U\left(\tilde{a}_{h}+\Delta \tilde{a}_{h}+E_{h}^{n e t}-k_{h}\left(\tilde{a}_{h}+\Delta \tilde{a}_{h}, \mathbf{X}\right)\right) \\
& +\beta \mathbb{V}_{h+1}\left((1+r) k_{h}\left(\tilde{a}_{h}+\Delta \tilde{a}_{h}, \mathbf{X}\right), \mathbf{X}^{\prime}\right) \geq \\
& \quad U\left(\tilde{a}_{h}+\Delta \tilde{a}_{h}+E_{h}^{n e t}-\tilde{k}\right)+\beta \mathbb{V}_{h+1}\left((1+r) \tilde{k}, \mathbf{X}^{\prime}\right) .
\end{aligned}
$$

Together with the fact that $k_{h}(\cdot, \mathbf{X})$ is weakly increasing and $\mathbb{V}_{h+1}\left(\cdot, \mathbf{X}^{\prime}\right)$ is strictly increasing implies $(7) \geq(6)$ as was to be shown.

I still need to show that $V_{h}$ is sub-differentiable, given that $\mathbb{V}_{h+1}$ is subdifferentiable. Clausen and Strub (2012) show that kinks do not cancel out under addition. Hence, it is sufficient to show that the upper envelope of a sub-differentiable function is sub-differentiable. ${ }^{36}$ When $V_{h}(\cdot, \mathbf{X})$ is the upper envelope of some sub-differentiable function, $f(a, K)$, with

\footnotetext{
${ }^{36} \mathrm{My}$ proof follows their Lemma \& where I replace the derivative with the subdifferential.
} 
$V_{h}\left(a^{0}, \mathbf{X}\right)=f\left(a^{0}, k\right):$

$$
f(a+\Delta a, k)-f(a, k) \leq V_{h}\left(a^{0}+\Delta a, \mathbf{X}\right)-V_{h}\left(a^{0}, \mathbf{X}\right) .
$$

It follows that $\partial_{D} f \in \partial_{D} V_{h}(\cdot, \mathbf{X})$ and consequently $V_{h}(\cdot, \mathbf{X})$ is sub-differentiable. The desired result follows directly: All non-differentiable points cannot be a solution to (1) and (2).

\section{Micro Elasticities}

Several papers asses the effects asset means-tested income support has on households' wealth accumulation with reduced form approaches. This section employs my model to perform policy experiments as those exploited by these papers. Replicating these experiment is beyond the scope of this paper. Households have characteristics which are not present in the model. Moreover, the time frame under consideration; thereby, the institutional setting, is not identical to the period studied in this paper. Nevertheless, comparing the implied estimates allows to get a feeling about the magnitude of potential differences.

Powers (1998) uses changes in states asset limits of the $A F D C$ program in 1981, to asses how state differences affect households' wealth accumulation in the years after the reform. Her sample consists of female headed households with an average age of 28 for whom she specifies the following regression:

$$
S_{i t}=\beta \Delta L_{i t}+\alpha X_{i t}+\epsilon_{i t},
$$

where $S_{i t}$ is savings of household $i$ between years 1978 and 1983, $\Delta L_{i t}$ is the change in the asset limit and $X_{i t}$ are household observables. She finds that increasing the limit by $\$ 1$ leads to a statistically significant 25 cents additional savings over the next five years.

To approximate her experiment within my framework, I increase the common asset threshold by inflation adjusted $\$ 446$, the average rise in the data reported by Powers (1998), and simulate for five years 28 year old high school dropouts, the dominant demographic group in her study. I compare their response in $S_{i t}$ to the same households in my baseline specification where $\bar{a}$ stays the same. The top panel in Table 8 shows that the model 


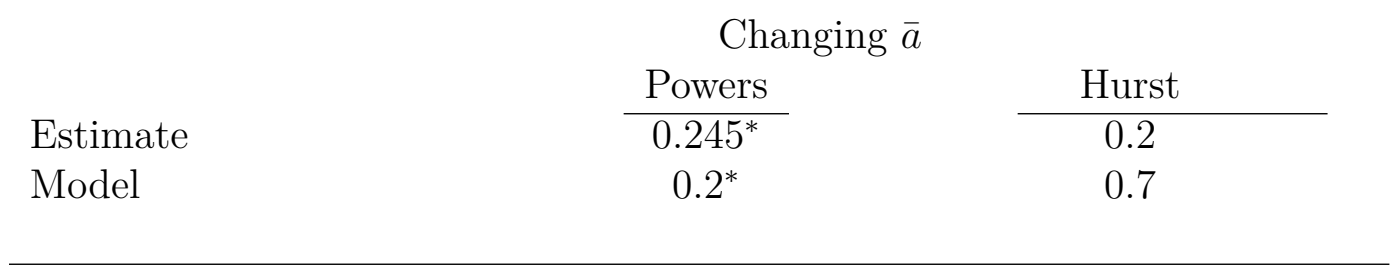

\section{Changing $T R$}

$\begin{array}{lcc} & & \text { Neumark } \\ & \text { Treatment } & \\ \text { Estimate } & -287^{*} & \\ \text { Model } & -1.2 & \end{array}$

\begin{tabular}{|c|c|c|c|c|c|}
\hline \multirow{4}{*}{$\begin{array}{l}\text { Estimate } \\
\text { Model }\end{array}$} & \multicolumn{5}{|c|}{ Zilliak } \\
\hline & All & Low & Medium & & High \\
\hline & -0.5 & 0.77 & -2.45 & & 3.05 \\
\hline & -0.58 & -1.3 & -1.2 & -0.6 & 0 \\
\hline
\end{tabular}

implied response turns out to be close to the reduced form estimate. Given the differences in setting, one would not expect a perfect fit between the two numbers. Yet, the comparison provides evidence that the model does not overstate the effect that asset means-testing has on wealth accumulation.

Hurst and Ziliak (2006) study the effect of the 1996 AF DC reform on single female headed households. They run a regression of the form:

$$
S_{i t}=\beta \Delta L_{i t}+\gamma \Delta L_{i t} D_{i t}+\alpha X_{i t}+\epsilon_{i t}
$$

where $S_{i t}$ is household's savings between 1996 and 2001, and $D_{i t}$ is a dummy that is one whenever a household is female headed with children. Besides demographics, $X_{i t}$ includes average household income and the change in household income. They find that changes in asset limits did not affect wealth accumulation over a five year period.

Again, I simulate an increase of $\bar{a}$ in my model by the average increase in the data $(\$ 1000)$. I follow households with the average age in the 
data (32) for five years. In the regression, being a high school dropout is supposed to proxy for the likelihood of participation. Table 8 shows that also the model implies an statistically insignificant response (0.7) of these households to the change in the asset limit. The important aspect to notice is that the theory does not unambiguously imply that higher asset limits should increase households' wealth accumulation. Higher limits imply that participation becomes more attractive to a larger range of households. Households with previously moderate wealth suddenly find it attractive to reduce their wealth to become eligible to the means-tested program. Moreover, higher asset limits effectively makes the welfare state more generous; thereby, they reduce the incentives for precautionary savings. The strength of these different incentives depend on households' age and are stronger for the somewhat older households studied by Hurst and Ziliak (2006) compared to Powers (1998).

A second strand of literature studies wealth outcomes resulting from different state legislation in the level of asset means-tested transfers. Neumark and Powers (1998) study the effect that state supplements to SSI have on the savings behavior of those aged $61-64$. They split their sample into likely and unlikely participants. They obtain participation likelihood from a first stage probit regression of $S S I$ participation on demographics, among them education and food stamp participation. In a second step, they estimate a regression of the form:

$$
S_{i j}=\alpha S U P P_{i j}+\beta P A R T_{i j}+\gamma P A R T_{i j} S U P P_{i j}+\epsilon_{i t},
$$

where $S_{i j}$ is individual savings between age $61-64$ in state $j, S U P P_{i j}$ is the state supplement, and $P A R T_{i j}$ is a dummy which is one when a household is predicted to have a high likelihood to participate in $S S I$. The identification strategy is to use differences in savings behavior of likely and unlikely participants within states and differences in savings behavior of likely participants between states. They find that increasing $S S I$ benefits by $\$ 100$, reduces savings between age $61-64$ by about $\$ 287$.

I proxy for likelihood of participation in $S S I$ by a dummy which is one when households receive means-tested transfers at age 61 and is low educated. Using the difference approach from Neumark and Powers (1998), 
I find that a reduction in savings of $\$ 1.2$. This estimate is outside the 95\% confidence interval of Neumark and Powers (1998). However, most of their identification comes from their finding that households having a low participation probability and live in states with low $S S I$ supplements save on average more ( $\alpha$ is positive). In fact, households with a high probability to participate save very similar across different states.

Finally, Ziliak (2003) studies the the log ratio of total household wealth ${ }^{37}$ to permanent income of the working aged population. He specifies the following regression:

$$
\frac{W_{i t}^{j}}{P_{i}^{j}}=\beta_{1} P T A_{i}^{j}+\beta_{2} P T_{i}^{j}+\beta_{2} P L_{i}^{j}+\beta_{2} X_{i t}^{j}+\epsilon_{i t}^{j},
$$

where $W_{i t}^{j}$ is the log of household wealth in state $j, P_{i}^{j}$ if the log of household permanent income, $P T A_{i}^{j}$ the log of permanent asset means-tested transfer income, $P T_{i}^{j}$ the log of permanent transfer income, and $P L_{i}^{j}$ is the log of permanent labor income. He computes $P_{i}^{j}$ as average total income over the observation period of a household. Similarly, he computes $P T A_{i}^{j}, P T_{i}^{j}$, $P L_{i}^{j}$ as households average incomes, but instruments for these with state legislation. $X_{i t}^{j}$ includes household observables and the maximum amount of states $A F D C$ and $S N A P$ benefits. This latter variable is the one to which I compare my model implications. He finds that this ratio is almost unaffected by state differences in $A F D C$ and $S N A P$ benefits.

Ziliak (2003) faces the problem that there may be unobserved household heterogeneity and uses a random effect model to identify the coefficients. The approach is not feasible in my case, because I am missing state variation in the instruments. Instead, I use a mean comparison between my baseline specification, and a specification with 10 percent higher $A F D C$ and $S N A P$ benefits to compute the true coefficients. The lower panel of Table 8 shows that both on average and for different education groups, the wealth response is close to zero.

\footnotetext{
${ }^{37}$ Different to my approach, he includes business equity into total household wealth.
} 


\section{E Numerical Algorithm}

My algorithm depends on the state the household is currently in. In regions where households are too wealthy and never want to participate in the means-tested program, I solve for optimal policy with the endogenous grid method proposed by Caroll (2006). In other parts of the state space, first order conditions are not necessarily unique. In theory, one knows all non-differentiabilities in the expected value function when computing the problem backwards and could compare all candidate points to the choice

$k=\frac{\bar{a}}{1+r}$. Theorem 2 establishes that the choice leading to the highest value is indeed the global optimum. However, uncertain earnings increases the number of non-differentiabilities quickly making it computationally expensive to allow for off-grid choices. As a compromise, I allow for a very fine asset grid for low asset choices and make it coarser towards higher asset states. In total, I allow for almost 9000 asset choices. Solving the household problem with Fortran 90 and a computing cluster with 28 workers takes about 1 hour.

Following the computation of optimal policies, I compute the median wealth to earnings ratio by simulating a history of 100000 households. I update the discount factor using bisection search. Finally, to reduce the simulation error when computing welfare measures, I compute the stationary distribution $\lambda$ using distribution function iteration. 


\section{References}

Bell, F. C. AND M. L. Miller (2002): "Life Tables for the United States Social Security Area 1900-2100," Actuarial Study 16, Social Security Administration.

Blundell, R., L. Pistaferri, and I. Preston (2008): "Consumption Inequality and Partial Insurance," American Economic Review, 98, 18871921.

Braun, A. R., K. A. Kopecky, And T. Koreshkova (2013): "Old, Sick, Alone, and Poor: A Welfare Analysis of Old-Age Social Insurance Programs," Working Paper 2013-2, Federal Reserve Bank of Atlanta.

Brown, J., J. B. Liebman, And J. Pollet (2008): "Appendix. Estimating Life Tables That Reflect Socioeconomic Differences In Mortality," in The Distributional Aspects of Social Security and Social Security Reform, ed. by M. Feldstein and J. B. Liebman, Chicago: University of Chicago Press.

Caroll, C. D. (2006): "The Method of Endogenous Grid Points for Solving Dynamic Stochastic Optimization Problems," Economic Letters, 91, 312-320.

Carroll, C. D., K. E. Dynan, And S. D. Krane (2003): "Unemployment Risk and Precautionary Wealth: Evidence from Households' Balance Sheets," The Review of Economics and Statistics, 85, 586-604.

Clausen, A. And C. Strub (2012): "Envelope Theorems for NonSmooth and non-Concave Optimization," mimeo, University of Pennsylvania.

Conesa, J. C., S. Kitao, And D. Krueger (2009): “Taxing Capital? Not a Bad Idea after All!" American Economic Review, 99, 25-48.

De Nardi, M., E. French, And J. B. Jones (2010): "Why Do the Elderly Save? The Role of Medical Expenses," Journal of Political Economy, 118, 39-75. 
Dynan, K. E., J. Skinner, And S. P. Zeldes (2004): "Do the Rich Save More?" Journal of Political Economy, 112, 397-444.

Federal Budget (2011): Budget of the U.S. Government Fiscal Year 2011.

French, E. And J. B. Jones (2011): “The Effects of Health Insurance and Self-Insurance on Retirement Behavior," Econometrica, 79, 693-732.

Golosov, M. and T. J. Sargent (2012): "Taxation, Redistribution, and Debt in Incomplete Market Economies with Aggregate Shocks," mimeo, Princeton.

Golosov, M. And A. Tsyvinski (2006): "Designing Optimal Disability Insurance: A Case for Asset Testing," Journal of Political Economy, 114, $257-279$.

Gruber, J. (1997): "The Consumption Smoothing Benefits of Unemployment Insurance," American Economic Review, 87, 192-205.

(2001): "The Wealth of the Unemployed," Industrial and Labor Relations Review, 55, 79-94.

Heathcote, J., K. Storesletten, And G. L. Violante (2014): “Optimal Tax Progressivity: An Analytical Framework," Working Paper 19899, NBER.

Hubbard, G. R., J. Skinner, And S. P. Zeldes (1994): "Expanding the Life-Cycle Model: Precautionary Saving and Public Policy," The American Economic Review, P\&YP, 84, 174-179.

(1995): "Precautionary Savings and Social Insurance," Journal of Political Economy, 103, 360-399.

Hurst, E. And J. P. Ziliak (2006): "Do Welfare Asset Limits Affect Household Saving? Evidence from Welfare Reform," Journal of Human Resources, 41, 46-71.

Kaplan, G. and G. L. Violante (2010): "How Much Consumption Insurance beyond Self-Insurance?" American Economic Journal: Macroeconomics, 2, 53-87. 
Kassabian, D., T. Vericker, D. Searle, and M. Murphy (2011): "Welfare Rules Databook: State TANF Policies as of July 2010," mimeo, The Urban Institute.

Krueger, D. And F. Kubler (2006): "Pareto-Improving Social Security Reform when Financial Markets are Incomplete!?" American Economic Review, 96, 737-755.

Low, H., C. Meghir, and L. Pistaferri (2010): "Wage Risk and Employment Risk over the Life Cycle," American Economic Review, 100, 1432-1467.

Meyer, B. D. (2002): "Unemployment and Workers' Compensation Programmes: Rationale, Design, Labour Supply and Income Support," Fiscal Studies, 23, 1-49.

Moffitt, R. A. (2003): NBER Macroeconomics Annual 2003: The Business Cycle and the Life Cycle, University of Chicago Press.

Neumark, D. And E. T. Powers (1998): "The Effect of Means-Tested Income Support for the Elderly on Pre-Retirement Saving: Evidence from the SSI Program in the U.S." Journal of Public Economics, 68, 181-206.

Pashchenko, S. and P. Porapakkarm (2013): "Work Incentives of Medicaid Beneficiaries and The Role of Asset Testing," mimeo, Uppsala University.

Pavoni, N. and G. L. Violante (2007): "Optimal Welfare-to-Work Programs," Review of Economic Studies, 74, 283-318.

Powers, E. T. (1998): "Does Means-Testing Welfare Discourage Saving? Evidence from a Change in AFDC Policy in the United States," Journal of Public Economics, 68, 33-53.

Rendahl, P. (2012): "Asset-based Unemployment Insurance," International Economic Review, 53, 743-770. 
Scholz, J. K., A. Seshadri, And S. Khitatrakun (2006): "Are Americans Saving "Otimally" for Retirement?" Journal of Political Economy, $114,607-643$.

Siegel, J. (2002): Stocks for the Long Run, McGraw-Hill.

Social Security Administration (2004): "Income of the Population 55 or Older, 2004," Tech. rep.

Storesletten, K., C. I. Telmer, And A. Yaron (2004): "Consumption and Risk Sharing over the Life Cycle," Journal of Monetary Economics, 51, 609-633.

Tauchen, G. (1986): "Finite State Markov-Chain Approximations to Univariate and Vector Autoregressions," Economics Letters, 20, 177-181.

Ziliak, J. P. (2003): "Income Transfers and Assets of the Poor," Review of Economics and Statistics, 85, 63-76. 